\title{
Going transnational? Candidates' transnational linkages on Twitter during the 2019 European Parliament elections
}

\author{
Sebastian Stier ${ }^{\mathrm{a}}$, Caterina Froio ${ }^{\mathrm{b}}$, and Wolf J. Schünemann ${ }^{\mathrm{c}}$ \\ ${ }^{a}$ GESIS - Leibniz Institute for the Social Sciences, Cologne, Germany; ${ }^{b}$ Sciences Po, Paris, \\ France; ${ }^{c}$ University of Hildesheim, Hildesheim, Germany
}

Preprint version of a paper published in West European Politics. Please cite https://doi.org/10.1080/01402382.2020.1812267

\begin{abstract}
How transnational are European Parliament (EP) campaigns? Building on research on the European public sphere and the politicisation of the EU, this study investigates to what extent the 2019 EP campaign was transnational and which factors were associated with 'going transnational'. It conceptualises Twitter linkages of EP candidates as constitutive elements of a transnational campaign arena distinguishing interactions with EP candidates from other countries (horizontal transnationalisation) and interactions with the supranational European party families and lead candidates (vertical transnationalisation). The analysis of tweets sent by EP candidates from all 28 member states reveals that most linkages remain national. Despite this evidence for the second-order logic, there are still relevant variations contingent on EU positions of parties, the adoption of the Spitzenkandidaten system and socialisation in the EP. The findings have implications for debates on the European public sphere and institutional reform proposals such as transnational party lists that might mitigate the EU's democratic deficit.
\end{abstract}

Keywords: Transnationalisation; politicisation; European Union; Spitzenkandidaten; Twitter 
European elections are regularly observed with baited breath (Braun and Popa 2018; Smith 1995). As the European Union (EU) still has to prove its democratic character in the eyes of many observers, direct elections of the European Parliament (EP) serve as litmus tests. So far, they have appeared to be suffering from a second-order logic in comparison to national elections. However, there was potential for an increased transnational character of the 2019 EP elections due to important changes in EU politics. First, the Spitzenkandidaten (lead candidates) system which increased the personalisation in EP election campaigns (Schmitt et al. 2015) was applied again. Linking the outcomes of national votes to the selection of the President of the European Commission has the potential to increase public awareness of EU affairs. Second, the political consequences of the multiple crises the EU has had to face, in particular the Great Recession and the refugee policy crises, increased the salience of EU issues in domestic debates (Hutter and Kriesi 2019; Hutter et al. 2016). Such crisis dynamics might also stimulate transnational campaign activity. Third, EU politics had become more contested notably by radical right populist parties (RRPPs) (Pirro et al. 2018). RRPPs engaged in Eurosceptic campaigns beyond national borders, at times creating cross-national linkages and mobilising on transnational issues such as EU integration, migration, and economic governance (McDonnell and Werner 2019; Van Hauwaert 2019).

This afrticle addresses three gaps in extant research. First, existing literature regards politicisation mainly as the level of conflict on the EU in domestic politics. Hutter and Kriesi (2019: 1003-4) contend that 'the increasingly politically charged nature of European politics has its source primarily in national politics' and 'think it is essential to start with dynamics in national political arenas'. This paper moves beyond the national level by conceptualising and measuring the breadth of the transnational campaign arena, a political communication space consisting of transnational interactions between political actors. Second, research on transnational activity in EU politics has predominantly focused on institutional features. Scholars have put considerable emphasis on policy diffusion mechanisms and the establishment of transnational parties in 
the EP but overlooked the transnational linkages created by the campaign activities of individual candidates. Third, existing frameworks do not consider that new venues of political communication can mediate politicisation processes. Most research has relied on traditional sources - newspapers and party manifestos - neglecting that social media provide political actors with a new platform to discuss EU affairs in more interactive ways, bearing a transactional potential beyond national public spheres. Yet the potential of social media for transnational campaigning has to be empirically tested against the backdrop of the 'second-order' elections hypothesis (Reif and Schmitt 1980) that presumes a predominant orientation of political actors towards the national level, even during EP election campaigns. Specifically, we tackle two research questions:

1. To what extent are EP candidates' campaign interactions transnational?

2. Under what conditions do EP candidates engage in transnational campaign interactions?

The empirical analysis relies on more than half a million tweets sent during the 2019 EP election campaign by 2,799 candidates belonging to the major parties in the $28 \mathrm{EU}$ member states. The results show that the second-order logic still prevails, even on the elite-dominated platform Twitter, as EP candidates mostly create linkages to national actors. However, we find relevant variations in the likelihood to engage in the transnational campaign arena depending on parties' participation in the Spitzenkandidaten system and candidates' socialisation in the EP. EU positions of parties also matters, as candidates from Eurosceptic parties have a higher likelihood to create horizontal cross-national linkages with other EP candidates, whereas candidates from Europhile parties engage more vertically with transnational parties and lead candidates. While we focus on the 2019 EP election campaign on Twitter, the findings have implications for debates on the politicisation of the EU, an emerging European public sphere, and institutional reform proposals such as transnational party lists that might mitigate the EU's democratic deficit. 


\section{Transnational campaign activities in EP elections}

\section{Social media's potential for the transnationalisation of EU politics}

Theoretical work on the (missing) European public sphere has emphasised the role that media have played for Europeanisation processes (Habermas and Cronin 2012; Koopmans and Erbe 2004), notably in terms of the impact of EU politicisation on the emergence and development of a transnational arena (Statham and Trenz 2015). More recently, scholars have focused on the role of digital media in this process, highlighting social media's potential for political interactivity beyond national public spheres (Bennett et al. 2014), and thus as facilitators for transnationalisation (De Zúñiga 2015).

Optimistic accounts of social media's transnational potential have identified signs of a 'European Twittersphere' (Hänska and Bauchowitz 2019) and Twitter's potential 'to generate a European demos' (Ruiz-Soler et al. 2019: 1). However, despite a non-neglectable participation by users in cross-national debates (Bossetta et al. 2017; Froio and Ganesh 2019; Hänska and Bauchowitz 2019), social media's potential for transnationalisation should not be overestimated as they are used by a relatively tiny share of citizens for political purposes. Yet with its 'elitist' nature (Bossetta et al. 2017; Stier et al. 2018b), Twitter is a social network widely used by political actors, e.g., $85 \%$ of the Members of the European Parliament (MEPs) who served in 2015 and 2016 (Daniel et al. 2017). Accordingly, we study campaign activities by all candidates with a Twitter account who stood in the 2019 EP campaign for the major national parties.

Previous work on the use of social media by EP candidates and MEPs focused on the influence of formal institutions such as electoral systems (Daniel and Obholzer 2020; Daniel et al. 2017; Larsson 2015; Obholzer and Daniel 2016), EP candidates' campaign communication and how dynamics change with the unfolding campaign (Nulty et al. 2016), and the implications of incivility directed at candidates (Theocharis et al. 2016). Several studies using data from the 
2014 EP campaign looked at aspects related to our research questions. Nulty et al. (2016) considered cross-country Twitter hashtag use, Braun and Schwarzbözl (2019) focused on mentions of Spitzenkandidaten in Facebook communication by main party accounts, while Popa et al. (2020) used EP candidates' Spitzenkandidaten mentions on Twitter to explain the acquisition of political knowledge by party supporters. In a four-country study, Fazekas et al. (2020) revealed a limited engagement between EP candidates and the public with regard to EU issues. Finally, Daniel and Obholzer (2020) investigated @-mentions of Spitzenkandidaten made by sitting MEPs during the EP campaign 2019. Taken together, our study is the first one to systematically investigate various dimensions of transnational campaigning by all EP candidates.

\section{The transnational campaign arena}

The literature on EP election campaigns is mostly limited to the (comparative) study of national campaigns (Maier et al. 2016). As a result, there has been little research on whether transnational linkages between parties and candidates from different countries also structurally affect EP campaigning. To address this, we propose a multilevel conceptualisation incorporating multiple political arenas and their associated incentive structures. We take a supply side perspective by defining an arena as a political communication space consisting of linkages between political actors. In contrast to national elections where the arena is confined to national political and media systems, EP campaigns also configure a transnational campaign arena, a political communication space that transcends the borders of individual member states. The empirical focus of this paper is to investigate how this double nature of EP elections shapes the campaign behaviour of the main political actors, candidates on national party lists who are competing for seats in the EP. ${ }^{1}$

We follow Koopmans and Erbe (2004) to conceptualise the different but complementary types of interactions structuring transnational campaign activities: ${ }^{2}$ (1) horizontal transnational 
interactions between EP candidates from two different member states and (2) vertical transnational interactions between EP candidates and the main transnational reference points during the campaign, Transnational Parties (TNPs) or Spitzenkandidaten. ${ }^{3}$ This conceptualisation of the transnational campaign arena takes into account the emerging patterns of contestation and inter-party conflict that Laffan (2016) condensed into the term 'multilevel politics'.

\section{Engaging in the transnational campaign arena: Counter-forces and driving factors}

We analyse the campaign behaviour of EP candidates with two main goals in mind. First, we examine to what extent transnational campaign activities occurred during the 2019 EP elections. Second, we disentangle the main drivers of EP candidates' engagement in the transnational campaign arena, concentrating on core factors derived from the literature on EU politics.

\section{The logic of second-order elections}

Despite the transnational nature of EP elections, national institutional frameworks still shape political communication by various means: a shared language, pre-structured media markets (at least for legacy media), long established routines of social communication, and practices of collective memory (Kielmansegg 2003). Accordingly, empirical studies of the 'second-order' elections hypothesis are as old as direct elections of the EP (Reif and Schmitt 1980). Since then it has been repeatedly and convincingly tested for successive EP elections (Hix and Marsh 2011; Schmitt 2005; Weber 2007). The hypothesis expects voters and candidates to show only a weak orientation towards EU issues and a dominant one towards national concerns and actors. Instead of focusing on voting behaviour or issue orientation like much of the previous literature, we are interested in candidates' interactions on social media to understand whether the second order logic also pervades candidates' Twitter networks. While social media ease exchanges across borders, EP elections remain national elections in terms of their structure, organisation, and 
political competition, thus we still expect to see the second-order logic reflected in our empirical data.

H1: Most linkages in EP candidates' tweets are national.

\section{Politicisation}

Politicisation has become a core concept in political science and EU studies (see for a review Zürn 2019). Following the postfunctionalist turn in EU integration theory (Hooghe and Marks 2009), politicisation is defined as 'the process of more publicly visible contestation related to the various dimensions of European integration' (Hutter and Kriesi 2019: 997). Most importantly, the work of Hutter and colleagues demonstrates how political parties politicise EUrelated issues during national and EP elections (Hutter and Grande 2014; Hutter et al. 2016; Hutter and Kriesi 2019). Yet while scholars agree that politicisation involves two interrelated levels of politics - transnational and domestic (see for a discussion Schmidt 2019) - most existing contributions on the politicisation of the EU focus on the level of member states, thereby overlooking the increasingly relevant transnational dimension of European politics.

The few studies that took a combined perspective on politicisation and transnationalisation drew ambivalent conclusions. Risse (2014a: 164) defines politicisation in terms of 'framing issues as of common European concern' and differentiates between frames that refer to political or constitutional questions with the former likely to positively affect the development of transnational discourse and identity. In contrast, the party political conflict perspective of Grande and Kriesi (2014) tends towards a more pessimistic outlook. Their findings suggest that the new patterns of EU politicisation impede transnational visions and the formation of a European identity.

Empirical studies based on party manifestos and expert surveys have shown that there are important differences between parties with regard to the intensity of their EP campaigns as well 
as their orientation towards the EU (Hobolt and de Vries 2015; Spoon 2012). Specifically, emphasising parties' positions on the EU (and not just its salience) in political communication can serve (transnational and national) partisan goals. Europhile parties make emotional appeals with regard to a shared pan-European identity and a need to work together across borders. Populist radical right Eurosceptic parties rally for a 'Europe of Nations'. For parties at both poles of the politicisation spectrum, demonstrating to national audiences (citizens and journalists) on Twitter that they have allies at the supranational level or in other member states who share their goals can be a winning strategy. We therefore expect that the extent to which political parties have polarised (negative or positive) positions on EU integration, i.e., whether they politicise the EU (Hobolt and de Vries 2015; Hutter and Kriesi 2019) has an impact on Twitter communication.

Europhile parties regard EU institutions as legitimate and hold communicative channels via well-established TNPs. For instance, a party like the British Liberal Democrats positions itself as an issue entrepreneur (Hobolt and de Vries 2015) in the generally Eurosceptic British political party system. One way to publicly emphasise positive stances on the EU is to vertically link to transnational actors on Twitter. In contrast, transnational ties between Eurosceptic parties are not predominantly knot via the vertical level (McDonnell and Werner 2019).

H2a: Eurosceptic politicisation of the EU is negatively associated with the number of vertical transnational communicative linkages.

Meanwhile, Eurosceptic parties do not necessarily confine themselves to the national campaign arena. In fact, since the 1970s RRPPs have tried to forge 'pan-European nationalist alliances'(Halikiopoulou et al. 2012; Pirro et al. 2018), displaying master frame similarities between them (Van Hauwaert 2019). Based on this, it would indeed be likely to not just find dense cross-national networks among Europhile candidates on Twitter, but also 'European corps' of 
Eurosceptics who horizontally engage with each other. Therefore, we do not expect to see significant differences in horizontal transnational linkages depending on the EU position of a candidate's party.

H2b: Politicisation of the EU (Europhile and Eurosceptic) is not significantly associated with the number of horizontal transnational communicative linkages.

\title{
The role of the Spitzenkandidaten
}

One of the most visible recent institutional changes of the EU system is the so-called Spitzenkandidaten model that aimed to personalise European elections (Schmitt et al. 2015), and thereby increase transnational interest, participation in and the democratic legitimacy of EU politics. As Christiansen (2016: 997) argues, the Spitzenkandidaten model

\begin{abstract}
$[\ldots]$ created a new context for election campaigning: the very fact of having Spitzenkandidaten at the European level (in addition to the domestically leading candidates that many of the component parties nominated to head national lists) did insert a new transnational dimension in the process. [...] While such transnational campaigning was inevitably selective and conditioned by the limited time and financial resources available to the candidates, it nevertheless marked a small, yet significant departure from past experience when European election campaigns were largely a compartmentalised affair taking place within the boundaries of the respective member states.
\end{abstract}

Despite the transnationalising potential, empirical findings for the 2014 EP elections showed that parties either strategically emphasised or ignored Spitzenkandidaten in their manifestos and on Facebook (Braun and Popa 2018; Braun and Schwarzbözl 2019). Transferred to this paper, especially parties that have appointed a Spitzenkandidat can be expected to embrace the vertical transnational dimension in their election communication.

H3: Adopting the Spitzenkandidaten system is positively associated with the number of vertical transnational communicative linkages.

\section{Socialisation in EU politics}

Not all candidates engage equally in transnational campaigns. Various strands of EU integration theory have suggested that especially politicians working inside supranational institutions 
would 'shift their loyalties' from the national to the European level and develop more supranational attitudes and behaviour (Cotta 1984; Haas 1958). This assumption has been challenged, however, by scholars that once more point to the secondary character of European parliamentarism and the fact that candidates need to secure electoral success and/or party support at the domestic level (Scully 2005).

In addition, research on learning processes in politics (Gilardi 2010) suggests that experience acquired through socialisation in EU institutions influences politicians' behaviour and the way they communicate publicly (Lilleker and Koc-Michalska 2013: 197). Incumbents are thus part of denser professional networks at international scale than challengers. Hence, their campaign activities can be expected to reflect communicative routines and channels established during their mandate. Moreover, in addition to vote-seeking, incumbents are likely to be driven by an office-seeking rationale with respect to leadership positions within their own parliamentary group, the EP administrative hierarchy or other supranational institutions to be claimed after elections, most often by senior MEPs (Beauvallet and Michon 2010). This should motivate them to 'practice community' and engage in both transnational dimensions (horizontal and vertical).

H4: Being an incumbent MEP is positively associated with the number of horizontal and vertical transnational communicative linkages.

\section{Research design}

\section{Data}

Besides substantive reasons to focus on Twitter, a unique transnational medium, this data source also provides methodological advantages. In contrast to the much-studied party manifestos or news coverage that portrays political activity through journalistic filters, digital traces found on social media capture the actual dynamics of political communication. Social media provide a 
constant and comparable flow of messages from political actors that can further be matched with external information on individual candidates and their party. Finally, this data type is behavioural and thus captures candidate activities in a non-intrusive way, in contrast to other instruments such as candidate surveys.

Twitter is not only a relevant communication venue to study, but also closely mirrors general political behaviour by candidates. For instance, Barberá (2015) developed a scaling method based on Twitter data that puts elites and regular Twitter users onto a unified one dimensional space. He demonstrates that the ideological placement of politicians in the U.S. and European parties in five countries is similar to roll call data and expert surveys. While other research has shown that the affordances of different online platforms affect campaign communication, candidates' activity on Twitter more closely mirrors the general campaign agenda than their posts on Facebook (Stier et al. 2018a).

Our data covers the Twitter accounts of political actors from all 28 EU member states during the EP election campaign 2019 (Stier et al. 2020). Specifically, we focus on national EP candidates, Spitzenkandidaten (also those who do not run as a candidate on a European party list) and EU TNPs (not parliamentary groups). The Twitter accounts of these EP campaign elite actors were researched during April and May 2019 by national country experts who were part of the Euromanifesto Study. In order to keep the set of included parties comparable across countries and to mitigate potential difficulties in identifying the Twitter handles of candidates from fringe parties, we only included parties that received at least $2 \%$ of the national vote in the EP elections 2019. The tweets, incoming retweets and @-mentions of EP candidates were purchased from Twitter after the election. Compared to querying the Twitter API, buying the data ensures the completeness of the data. ${ }^{4}$ The research period is 23 April to 30 May 2019.

In total, a list of 6,500 actors was compiled of which 3,499 had a Twitter account. 2,799 EP candidates (excluding Spitzenkandidaten, who we assign to the EU level; see below) belonging to 204 national political parties sent at least one tweet during our research period of five weeks. 
In total, candidates produced 516,351 tweets, of which 284,667 were retweets, that means a direct share of a message originally sent by another Twitter account (see below). Detailed descriptions of EP candidates' Twitter activity can be found in Online Appendix Section 1.

\section{Measures and methods}

Dependent variables. We use two behavioural measures to operationalise transnationalisation in EP candidates' Twitter activity.

- @-mentions of Twitter accounts, a feature allowing users to discuss with each other. Here we also included quoted tweets, a feature allowing a user to display a specific message of an account and add a message above it. We expect both types of @-mentions to be used for criticism of political opponents as well (Conover et al. 2011).

- Retweets of Twitter accounts, a feature allowing users to share messages of another account with her/his own followers. While there are debates about whether retweets can unambiguously be regarded as signals of support for a cause or a statement, it serves well as a metric for identifying users that seek to embed themselves in a particular discursive context (Murthy 2012: 1068), such as an election campaign.

We extracted every account dyad (sender and receiver) of an @-mention or retweet from the raw Twitter data. We excluded TNPs and Spitzenkandidaten from the list of senders, as our main interest is not on their active communication which is per se transnational. We also removed dyads in which candidates @-mentioned and retweeted their own Twitter account. After applying these filters, 14.2\% of all @-mentioned and 12.7\% of all retweeted accounts were national EP candidates, Spitzenkandidaten and TNPs. Taken together, our unit of analysis are national EP candidates and to which extent they refer to Twitter accounts of other elite actors during the EP campaign. Based on this conceptualisation we constructed three dependent variables: 
- Transnational, vertical dimension. @-mentions or retweets of TNPs or Spitzenkandidaten. This includes references to Spitzenkandidaten by candidates from their own country, e.g., a German CDU candidate mentioning the leading candidate of the EPP Manfred Weber who is also German.

- Transnational, horizontal dimension. A candidate referencing a candidate from another country via@-mention or retweet, excluding Spitzenkandidaten who we treat as vertical transnational actors.

- National. A candidate referencing another candidate from her/his country via @-mentions or retweets, excluding mentions of Spitzenkandidaten from the same country that are counted as vertical transnational actors.

The coding is mutually exclusive, i.e., a dyad can only be assigned to one of the three categories. Yet, a considerable share of tweets referencing the Spitzenkandidaten from their home countries might not just address their campaign activities and policy positions as supranational candidates but also emphasise their national roles. In consequence, our approach might overestimate the actual degree of transnationalisation in EU campaigns, but we will show that the main results hold with a more restrictive operationalisation.

It could be argued that a conceptualisation of the transnational campaign arena should include other actors in addition to EP candidates, e.g., national parties or politicians. However, such an extensive definition would blur the boundaries between actors that primarily engage in the EP campaign and accounts that only under specific circumstances become relevant EP campaign actors. Moreover, an approach like counting free text mentions of actors might work well for some targets (e.g., 'Weber'), but inputting the names of all EP candidates (e.g., 'Müller' or 'Smith') would result in a large number of false positives and not necessarily reveal campaign interactivity but also 'topical' references of persons. Given these measurement issues, our approach stands out as a 'minimalist' but still the most direct operationalisation of engagement in the transnational campaign arena. Finally, relying on standardised account references derived 
from the Twitter meta-data is the only feasible and most reliable way to conduct an analysis of more than half a million multilingual tweets. A robustness test that compares the @-mention and free text mention approaches is in Online Appendix Section 6.

Independent variables. We coded as dummy variables whether the TNP to which a candidate's party belongs nominated a Spitzenkandidat and whether a candidate was a sitting MEP during the eighth legislative period of the EP from 2014 to 2019.

We use the Chapel Hill Expert Surveys (CHES, Polk et al. 2017) to measure party positions on the EU. In order to maximise data coverage, we merged data from the CHES 2014 and 2017 (which was prioritised), even though this meant including partly outdated information. We could find a match in the CHES data for 172 out of 216 national parties in our data and $87 \%$ of candidates who tweeted at least once during the campaign. ${ }^{5}$ The CHES data covers $82 \%$ of all the tweets in our data. ${ }^{6}$ The two CHES items we use are the salience of the EU in a party's communication and the position of the party's leadership on European integration (Hutter and Kriesi 2019: 1005). This 'politicising party' measure is constructed by multiplying the salience of the EU in political communication of party $X$ with the polarisation (or, synonymously, distinctiveness) of its EU position. The polarisation of party X's EU position is the mean position of all parties in a political system (minus party $X$ ) subtracted by the EU position of party $X$. Therefore, positive values on the polarisation index indicate Eurosceptic, negative values signal Europhile positions (Hobolt and de Vries 2015; Hutter and Kriesi 2019: 1007). Both variables were mean centred before multiplying them in the interaction term. Online Appendix Section 2 shows visualisations of the EU politicisation variable.

Control variables. We include control variables that could affect the relationship between our independent variables and the likelihood to engage in transnational activities. At the party level, we include the ideological position in the left-right space taken from CHES. We use ParlGov data (Döring and Manow 2019) to control for the vote share of a party or electoral coalition in the previous national election, ${ }^{7}$ and whether it was participating in the national 
government during the EP election campaign. At the candidate level, we control for own activity (number of tweets, logged) and gender. We also include a dummy for all candidates leading (sub)national party lists, as these leading politicians might have incentives to represent their party beyond the national context. ${ }^{8}$ Following previous research (Giebler and Wessels 2010; Theocharis et al. 2016), we calculated a measure of electoral viability for each candidate. We took survey-based predictions made in April 2019 regarding the EP seats each national party would win (Cunningham et al. 2019) to categorise the electoral chances of each candidate as 'safe', 'doubtful', or 'unpromising' according to their position on national party lists. ${ }^{9}$ Descriptive statistics and correlations are shown in Online Appendix Section 3.

\section{Results}

We first present descriptive results on the transnationalisation of EP campaigns, before explaining the identified patterns using multivariate regression analyses.

\section{Descriptive results}

Figure 1 shows the share of each campaign level that was addressed in the 47,675@-mention dyads and 35,378 retweet dyads where the target is on our list of EP campaign elite actors. Candidates overwhelmingly interacted with other candidates from the same country and only rarely addressed transnational actors (vertically) or their counterparts (horizontally) from other countries. The sheer number of domestic interactions clearly signals that the primary political arena for EP campaigns is still national, supporting the second-order election hypothesis $H 1$. 

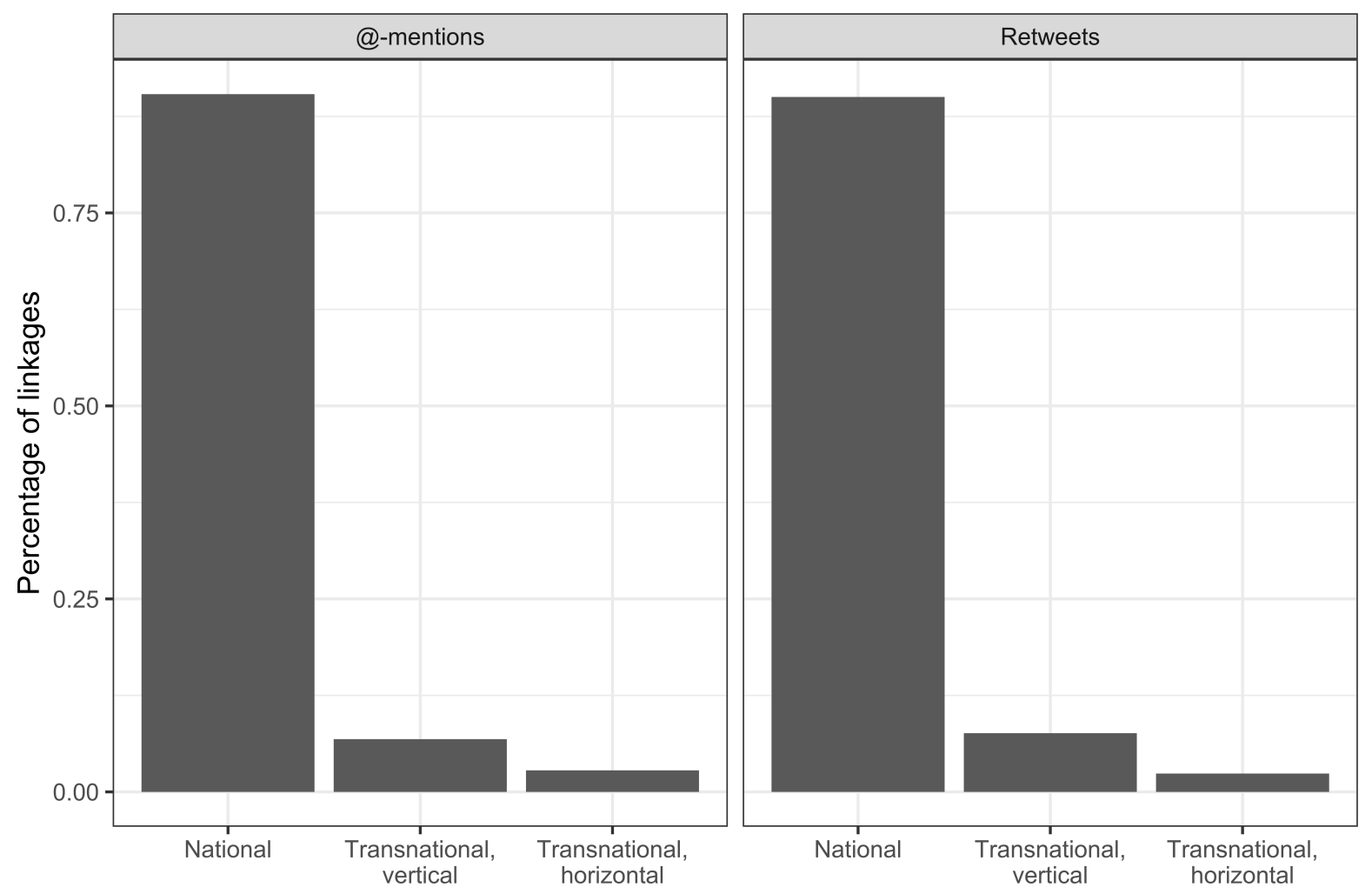

Type of linkage

Figure 1. Types of communicative linkages in tweets by EP candidates.

The data allow us to further investigate which referenced actor types are most constitutive for the transnational campaign arena. In Figure 2, the horizontal dimension of transnationalisation is again operationalised exclusively through cross-country interactions of candidates (like in Figure 1), but the vertical dimension is further disaggregated into TNPs and Spitzenkandidaten. The latter soak up even higher shares of transnational linkages via @-mentions than the TNPs and an equal share of retweets. Considering that not all European parties nominated transnational lead candidates and that TNPs have been established decades ago, this finding is noteworthy. Many EP candidates across Europe indeed incorporated the new political logic into their campaigns and regularly referred to the Twitter accounts of lead candidates. The Spitzenkandidaten system thus contributes to an integration of the transnational political arena. 


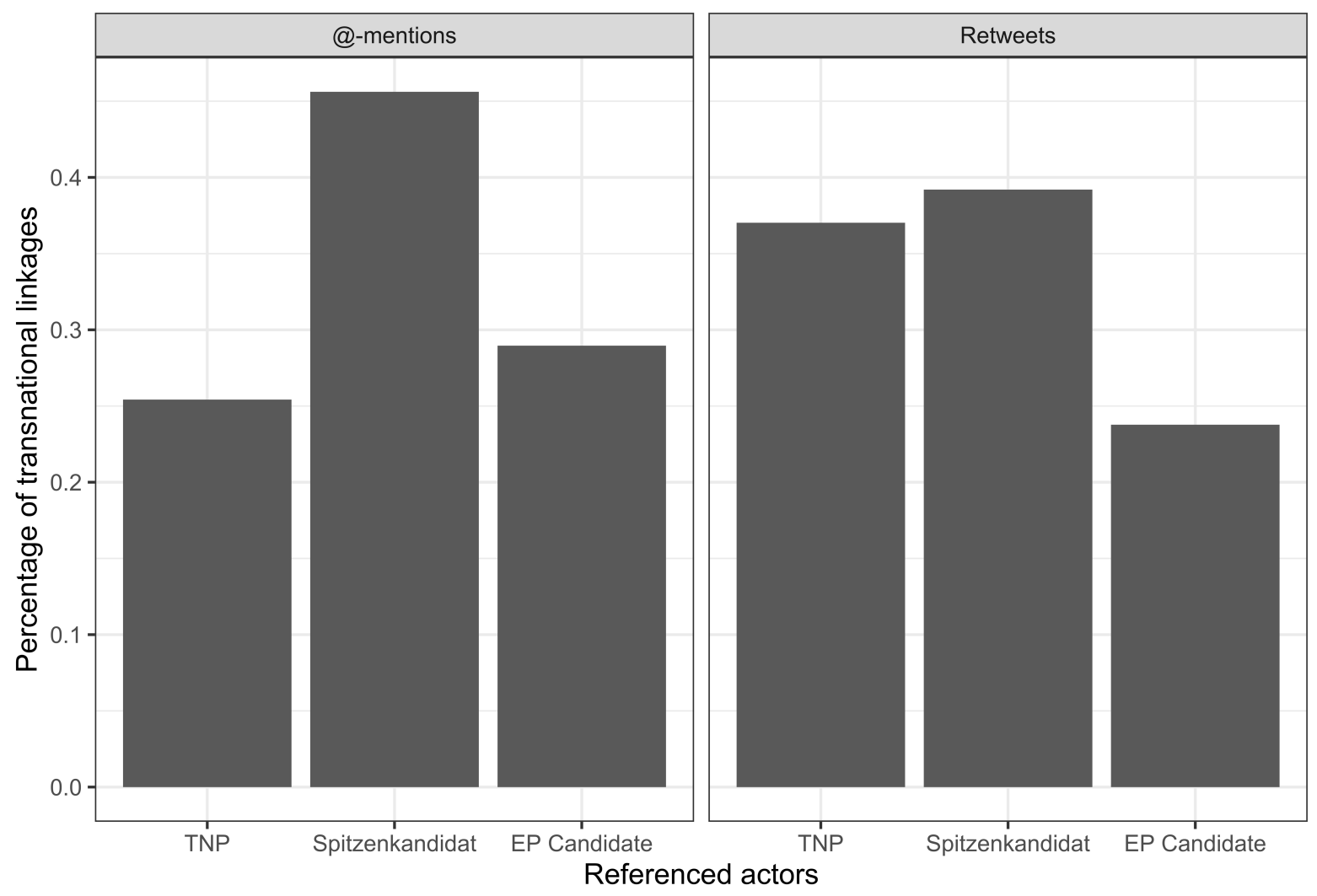

Figure 2. Types of transnational communicative linkages in tweets by EP candidates.

While we will work with more fine-grained variables measured at the level of national parties in our multivariate models, looking at the variation of these patterns across TNPs supports the validity of the transnationalisation indicators. Figure 3 shows that candidates from the Europhile parties with ambitions to promote one of their lead candidates to the presidency of the EU Commission (ALDE, EPP, and PES) prominently emphasise Spitzenkandidaten in their tweets (H3). In contrast, candidates of RRPPs grouped in the MENF that did not nominate a Spitzenkandidat never retweet one, but occasionally @-mention a Spitzenkandidat, supposedly as a negative campaigning tactic. 

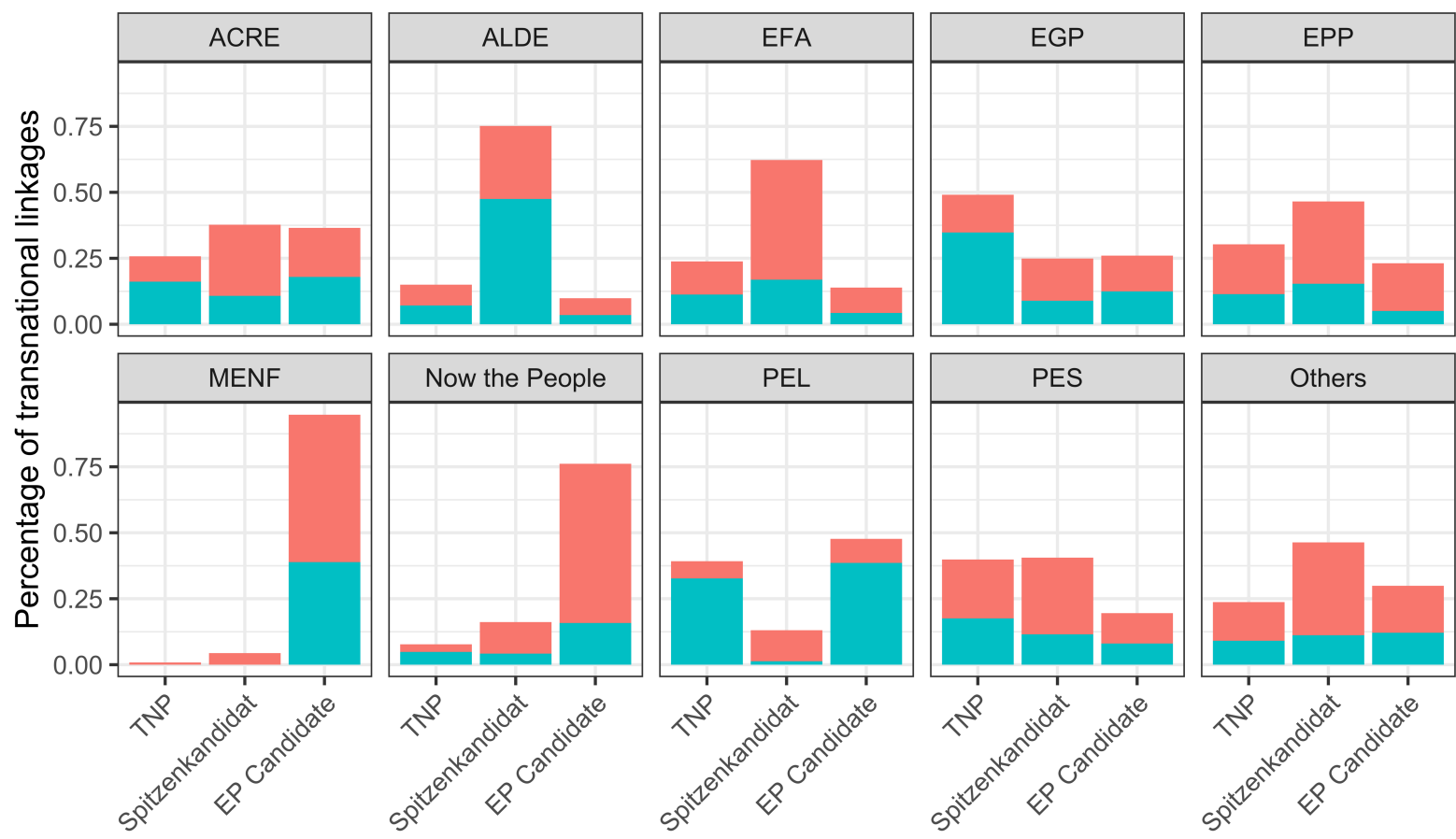

Referenced actors

@-mentions Retweets

Figure 3. Types of transnational communicative linkages in tweets by EP candidates, aggregated by TNP.

Note: Abbreviations of party names: ACRE $=$ Alliance of European Conservatives and Reformists; ALDE $=$ Alliance of Liberals and Democrats for Europe; EFA = European Free Alliance; EGP = European Green Party; EPP = European People's Party; MENF = Movement for a Europe of Nations and Freedom; PES = Party of European Socialists; PEL = Party of the European Left; Others = Candidates from parties without TNP affiliation, independent candidates or minor TNPs such as the European Pirate Party.

To put these results on a more robust footing, we next turn to multivariate analyses adding variables on individual EP candidates and their parties.

\section{Multivariate results}

As our main dependent variables, we construct counts of all @-mentions and retweets per candidate for each type of linkage (national, transnational vertical, transnational horizontal). Since the outcome measures are skewed (i.e., some candidates posted many, others no transnational tweets at all), we apply a count regression model. The overdispersion parameter is significant in Likelihood ratio tests for each of the models (each $p<0.001$ ), which indicates that negative binomial regressions are preferable over Poisson models. In order to account for the hierarchical data structure, we nest candidates within parties and also include country dummy variables. 
Table 1. Regression models of national, horizontal and vertical communicative linkages.

\begin{tabular}{|c|c|c|c|c|c|c|c|c|c|}
\hline & \multicolumn{3}{|c|}{ National } & \multicolumn{3}{|c|}{ Horizontal } & \multicolumn{3}{|c|}{ Vertical } \\
\hline & (1) & (2) & (3) & (4) & (5) & (6) & (7) & (8) & (9) \\
\hline \multirow{4}{*}{$\begin{array}{l}\text { TNP has a Spitzen- } \\
\text { kandidat } \\
\text { Incumbent }\end{array}$} & 0.14 & 0.20 & 0.16 & -0.30 & 0.15 & 0.40 & $1.64^{* * *}$ & $1.07^{* * *}$ & $1.15^{* * *}$ \\
\hline & $(0.13)$ & $(0.15)$ & $(0.15)$ & $(0.25)$ & $(0.27)$ & $(0.27)$ & $(0.24)$ & $(0.26)$ & $(0.27)$ \\
\hline & -0.02 & -0.02 & -0.02 & $0.67^{* * *}$ & $0.62^{* *}$ & $0.64^{* * *}$ & 0.14 & 0.15 & 0.15 \\
\hline & $(0.07)$ & $(0.07)$ & $(0.07)$ & $(0.19)$ & $(0.19)$ & $(0.19)$ & $(0.14)$ & $(0.14)$ & $(0.14)$ \\
\hline \multirow[t]{2}{*}{ EU polarisation } & & 0.06 & 0.04 & & $0.29^{*}$ & $0.47^{* * *}$ & & $-0.51^{* * *}$ & $-0.45^{* * *}$ \\
\hline & & $(0.07)$ & $(0.07)$ & & $(0.12)$ & $(0.13)$ & & $(0.12)$ & $(0.13)$ \\
\hline \multirow[t]{2}{*}{ EU salience } & & 0.06 & 0.05 & & $0.79^{* * *}$ & $0.84^{* * *}$ & & -0.23 & -0.22 \\
\hline & & $(0.08)$ & $(0.08)$ & & $(0.15)$ & $(0.14)$ & & $(0.14)$ & $(0.14)$ \\
\hline \multirow{2}{*}{$\begin{array}{l}\text { EU polarisation } X \mathrm{EU} \\
\text { salience }\end{array}$} & & & 0.06 & & & $-0.28^{* *}$ & & & -0.13 \\
\hline & & & $(0.06)$ & & & $(0.11)$ & & & $(0.11)$ \\
\hline \multirow[t]{2}{*}{ Ideology (left/right) } & 0.01 & 0.00 & -0.00 & -0.07 & $-0.16^{* * *}$ & $-0.13^{* *}$ & -0.07 & -0.02 & -0.01 \\
\hline & $(0.02)$ & $(0.02)$ & $(0.03)$ & $(0.05)$ & $(0.04)$ & $(0.04)$ & $(0.04)$ & $(0.04)$ & $(0.04)$ \\
\hline \multirow[t]{2}{*}{ National vote share } & -0.00 & -0.00 & -0.00 & 0.01 & 0.01 & 0.01 & -0.02 & -0.01 & -0.01 \\
\hline & $(0.01)$ & $(0.01)$ & $(0.01)$ & $(0.01)$ & $(0.01)$ & $(0.01)$ & $(0.01)$ & $(0.01)$ & $(0.01)$ \\
\hline \multirow{2}{*}{$\begin{array}{l}\text { National government } \\
\text { participation }\end{array}$} & $-0.26^{*}$ & -0.24 & -0.24 & -0.36 & -0.36 & -0.34 & 0.05 & -0.06 & -0.06 \\
\hline & $(0.13)$ & $(0.13)$ & $(0.13)$ & $(0.26)$ & $(0.23)$ & $(0.22)$ & $(0.24)$ & $(0.22)$ & $(0.22)$ \\
\hline \multirow{2}{*}{$\begin{array}{l}\text { (Sub)national lead } \\
\text { candidate }\end{array}$} & $-0.33^{* * *}$ & $-0.33^{* * *}$ & $-0.33^{* * *}$ & 0.39 & 0.44 & 0.40 & 0.13 & 0.15 & 0.15 \\
\hline & $(0.08)$ & $(0.08)$ & $(0.08)$ & $(0.25)$ & $(0.25)$ & $(0.25)$ & $(0.18)$ & $(0.18)$ & $(0.18)$ \\
\hline \multirow{2}{*}{ Male } & $-0.13^{* *}$ & $-0.13^{* *}$ & $-0.13^{* *}$ & -0.07 & -0.09 & -0.08 & -0.15 & -0.14 & -0.14 \\
\hline & $(0.04)$ & $(0.04)$ & $(0.04)$ & $(0.12)$ & $(0.13)$ & $(0.13)$ & $(0.09)$ & $(0.09)$ & $(0.09)$ \\
\hline \multirow[t]{2}{*}{ Viability: safe } & -0.16 & -0.16 & -0.16 & 0.07 & 0.12 & 0.13 & 0.02 & 0.01 & 0.01 \\
\hline & $(0.09)$ & $(0.09)$ & $(0.09)$ & $(0.24)$ & $(0.24)$ & $(0.24)$ & $(0.18)$ & $(0.18)$ & $(0.18)$ \\
\hline \multirow{2}{*}{$\begin{array}{l}\text { Viability: } \\
\text { Unpromising }\end{array}$} & $-0.21^{* *}$ & $-0.21^{* *}$ & $-0.21^{* *}$ & -0.10 & -0.07 & -0.08 & -0.22 & -0.21 & -0.20 \\
\hline & $(0.07)$ & $(0.07)$ & $(0.07)$ & $(0.20)$ & $(0.20)$ & $(0.20)$ & $(0.15)$ & $(0.15)$ & $(0.15)$ \\
\hline \multirow{2}{*}{$\begin{array}{l}\text { Total tweets sent } \\
\text { (logged) }\end{array}$} & $0.93^{* * *}$ & $0.93^{* * *}$ & $0.93^{* * *}$ & $1.18^{* * *}$ & $1.15^{* * *}$ & $1.16^{* * *}$ & $1.00^{* * *}$ & $1.00^{* * *}$ & $1.00^{* * *}$ \\
\hline & $(0.02)$ & $(0.02)$ & $(0.02)$ & $(0.06)$ & $(0.06)$ & $(0.06)$ & $(0.04)$ & $(0.04)$ & $(0.04)$ \\
\hline
\end{tabular}




$\begin{array}{lccccccccc} & -2.31^{* * *} & -2.23^{* * *} & -2.18^{* * *} & -5.03^{* * *} & -3.87^{* * *} & -4.04^{* * *} & -5.30^{* * *} & \begin{array}{c}-5.44^{* * *} \\ (0.5)\end{array} & -54^{* * *} \\ \text { Intercept } & (0.37) & (0.38) & (0.39) & (0.76) & (0.71) & (0.70) & (0.71) & (0.70) & \text { Yes } \\ & \text { Yes } & \text { Yes } & \text { Yes } & \text { Yes } & \text { Yes } & \text { Yes } & \text { Yes } & \text { Yes } & \text { Yes } \\ \text { Country fixed Effects } & 14978.08 & 14980.84 & 14981.96 & 3702.57 & 3677.58 & 3673.69 & 6078.24 & 6065.66 & 6066.30 \\ \text { AIC } & -7449.04 & -7448.42 & -7447.98 & -1811.29 & -1796.79 & -1793.84 & -2999.12 & -2990.83 & -2990.15 \\ \text { Log Likelihood } & 2435 & 2435 & 2435 & 2435 & 2435 & 2435 & 2435 & 2435 & 2435 \\ \text { Num. obs. } & 167 & 167 & 167 & 167 & 167 & 167 & 167 & 167 & 167 \\ \text { Num. groups: party } & 0.25 & 0.24 & 0.24 & 0.57 & 0.33 & 0.27 & 0.75 & 0.59 & 0.57 \\ \text { Var: party (Intercept) } & 0.25 & \end{array}$

Note: Results from negative binomial regression models. Hierarchical models with candidates nested in parties. The reference category for viability is 'doubtful'. ${ }^{* * *} \mathrm{p}<0.001 ;{ }^{* *} \mathrm{p}<0.01 ;{ }^{*} \mathrm{p}<0.05$. 
The main results are presented in a stepwise fashion in Table 1. The respective Model 1 includes only the Spitzenkandidaten and MEP incumbency dummies in addition to the control variables; Model 2 adds EU polarisation and EU salience; in Model 3 the two terms are interacted as a measure of EU politicisation.

We find that candidates from parties whose TNP nominated a Spitzenkandidat have a higher share of vertical transnational communicative linkages, in line with the descriptive patterns in Figure 3, thereby confirming $H 3$. The effect of having a Spitzenkandidat is not significantly related to horizontal and national linkages. The results only partly confirm $H 4$, as being an MEP incumbent is strongly associated with more horizontal linkages, but the relationship is not significant in case of vertical linkages.

Eurosceptic party positions with regard to the EU, i.e., high values on the EU Polarisation index, are positively associated with horizontal linkages (Model 5) and negatively associated with vertical linkages (Model 8). In addition, Figure 4 visualises to what extent the predicted marginal effect of EU Polarisation varies across levels of EU Salience (Brambor et al. 2006). The plot shows that there are no significant differences depending on the levels of $E U$ Salience (visualised are the predictions for the mean, one standard deviation below and above the mean of EU Salience), but that parties' EU positions still matter. Candidates of parties with anti-EU positions are less likely to engage in the vertical dimension of the transnational campaign arena (H2a). However, in contrast to $H 2 b$ that predicted an insignificant association of horizontal linkages with positive as well as negative EU politicisation, we find that Eurosceptic parties have an even higher likelihood to engage horizontally with candidates from other countries. A qualitative look at the data helps illustrate this pattern: the two national parties with the highest amount of horizontal linkages (153) among each other are the far-right Eurosceptic parties Lega $($ CHES EU position $=1.5$ on a scale from 1 to $7 ; M=4.77)$ and Rassemblement National (1.05). On the far-left Eurosceptic end of the political spectrum, there is a cluster consisting of La 
France Insoumise (2.25), the Swedish Vänsterpartiet (2.47) and Danish Red-Green Alliance (1.82) that regularly linked to each other horizontally.

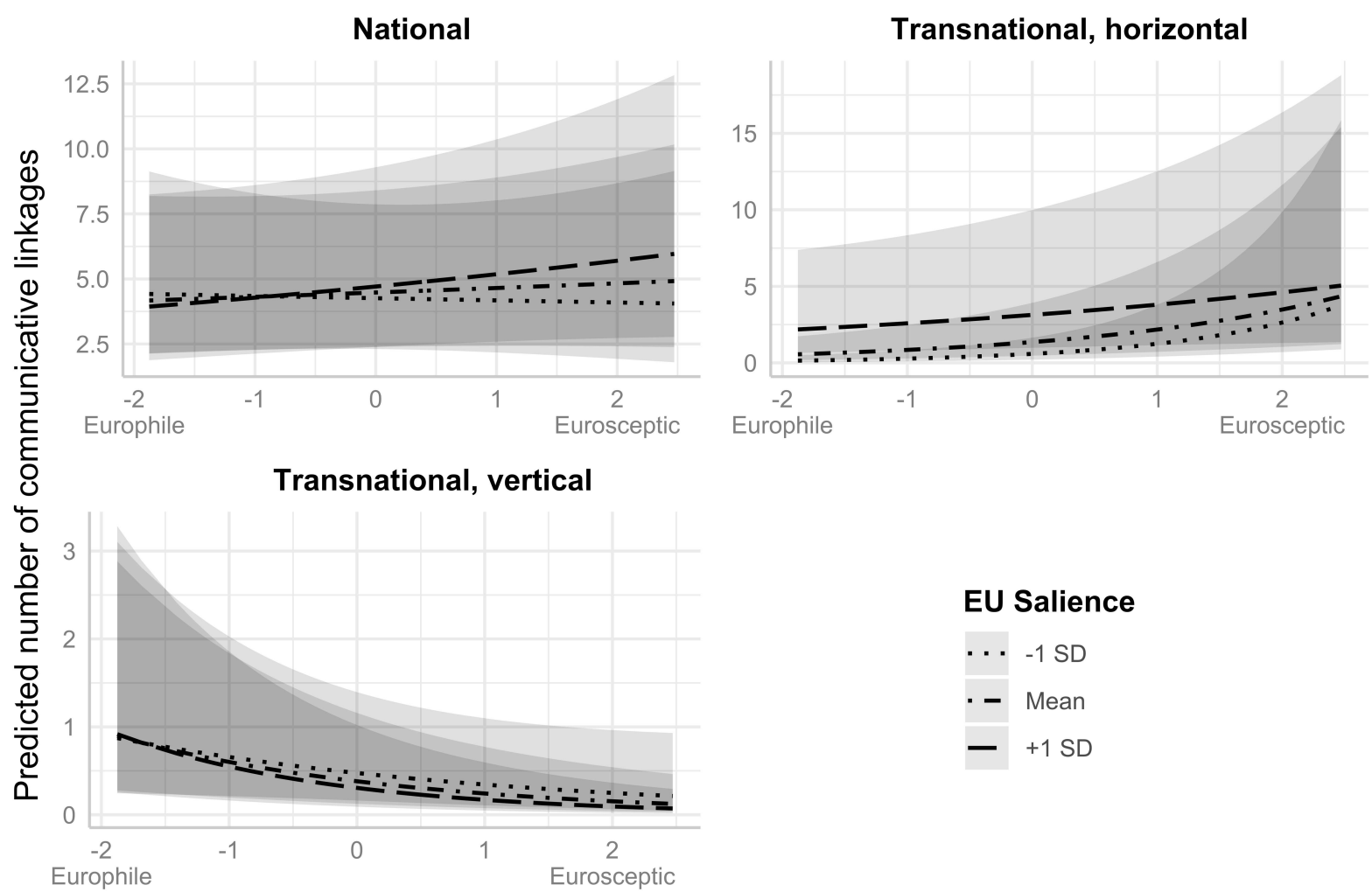

EU Polarisation

Figure 4. Predicted number of linkages for the interaction EU Polarisation $X$ EU Salience). Note: Output from Models 3, 6 and 9 in Table 1. Marginal effects including 95\% confidence intervals are shown for the mean, one standard deviation below and above the mean value of EU Salience.

\section{Robustness tests and tweet content}

We conducted several robustness tests. Since our measurement of vertical linkages includes linkages to a Spitzenkandidat by EP candidates from his/her own country, this might result in an overestimation of transnational linkages. Additional analyses in Online Appendix Section 4 demonstrate that the results still hold when subtracting national references from the count of vertical linkages, for instance, by counting a reference of Frans Timmermans by a Dutch EP candidate as a national linkage. In addition, the main results hold when using robust standard errors clustered by party instead of a hierarchical model; when operationalising the dependent 
variables as the percentage of tweets in each linkage category among all tweets sent by a candidate; or in hierarchical regression models with three levels instead of country dummies (with candidates nested in parties that are nested in countries).

In order to better understand the second-order nature of EP campaigns, we also introduce two additional baselines (Online Appendix Section 5). First, we applied the identical methodology to national party accounts (e.g., @Conservatives, @CDU) and found that these linkages are six times more frequent than transnational linkages, but still only about half as frequent as linkages to national EP candidates. Second, we replicated the methodology using a dataset of tweets sent by the same set of candidates after the constitution of the Ninth legislative period of the EP on 1 July 2019. Compared to the results for the campaign period, Figure A9 reveals considerable stability, but higher shares of horizontal linkages at the expense of national linkages. On the one hand, this finding indicates that (former) EP candidates tune down their domestic efforts during non-campaign periods and instead invest more in their transnational professional networks (especially MEPs). On the other hand, given the high normative expectations with regard to their transnationalising character, the observation that direct EP elections at least in their current form - tend to nationalise the interaction routines of involved actors compared to non-election periods lends even stronger support to the second-order hypothesis $H 1$ than the findings from the campaign period.

While all vertical and horizontal linkages, even banal ones, can help integrating a transnational arena, it is still an intriguing question how substantively meaningful for European politics vertical and horizontal linkages are. Based on previous research on EU coverage in newspapers (Adam et al. 2019), lists of EU-related keywords were compiled for all languages. We performed a dictionary analysis to investigate their occurrence in all tweets that include at least one linkage, i.e., an @-mention of another account. ${ }^{10}$ Figure 5 demonstrates that $43.6 \%$ of tweets containing a vertical linkage also include at least one reference to the EU and its institutions, compared to the significantly lower share of $39.0 \%$ for horizontal and $28.1 \%$ for national 
linkages. Only $21.5 \%$ of tweets where other accounts are embedded include at least one EUrelated keyword. We take this as evidence that by measuring linkages between actors we pick up meaningful signals of a transnational discourse on EU institutions, politics and governance.

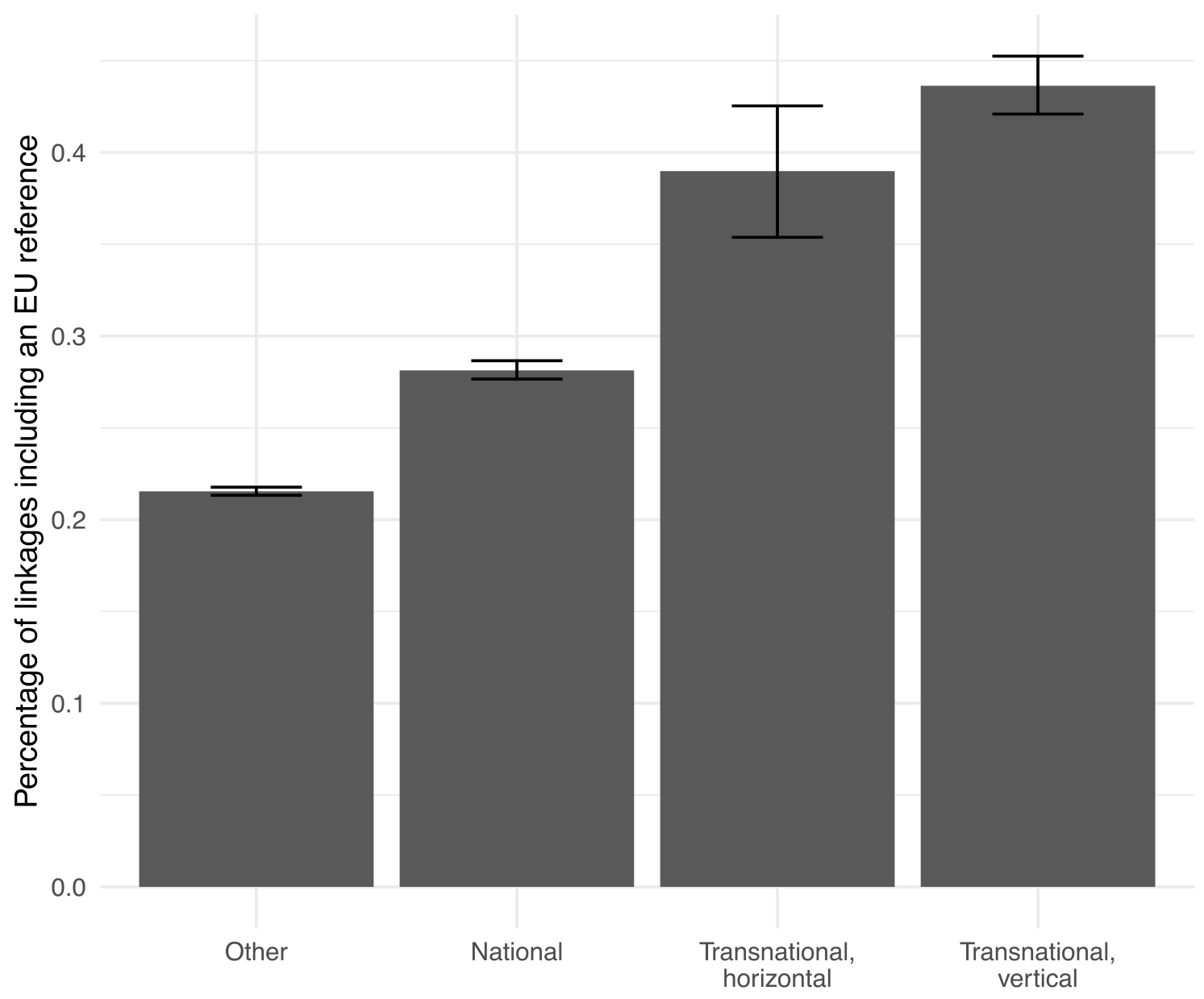

Figure 5. EU-related keywords in tweets containing different types of communicative linkages Note: Confidence intervals were calculated from 10,000 bootstrap runs.

Finally, we exploited the rare last names of the Spitzenkandidaten to compare the @-mention-based conceptualisation of linkages to free text mentions ('weber', 'timmermans', etc.) in the tweets sent by EP candidates (excluding retweets). The comparison in Online Appendix Section 6 revealed no systematic deviations between string mentions and @-mentions of Spitzenkandidaten but that false positives are already present (e.g., for (Nicola) 'Beer'), which would become severe when searching for a larger set of candidate names. This lends substantive and methodological support for our account-based measurement of engagement in the transnational campaign arena. 


\section{Conclusions}

This study has investigated to what extent EP candidates' campaign interactions are transnational and under what conditions EP candidates engage in the transnational campaign arena. Following research on European public spheres, it would be misleading to simply expect transnational activity to take place in some kind of 'artificial supranational space' located 'above and beyond local-, national-, or issue-specific public spheres' (Risse 2014b: 10). Therefore, we introduced the transnational campaign arena as a communicative sphere that cross-cuts the national and supranational levels. With our approach to measure transnational communicative linkages via Twitter, we gained novel insights into the structural features of campaigning in this multilevel arena. Our findings first lend support to the well-established second-order election hypothesis: candidates primarily direct their campaign communication towards the national arena, even on the transnational, elite-dominated social network Twitter. Given the national character of EP election campaigns in which candidates' Twitter use is embedded, this is to be expected. The comparison to a non-campaign period even indicates that the nationally structured EP campaigns lower the incentives for politicians to engage transnationally, but this finding is preliminary and warrants further research.

A more nuanced picture emerged when concentrating on the drivers of transnational communication on Twitter. We observed that the Spitzenkandidaten receive even more vertical transnational linkages than the much-longer established TNPs. This suggests that the Spitzenkandidaten system might serve as a relay for transnational activity that could pave the way for further institutional reform. To pour some cold water into this affirmative conclusion, it is important to note that the interaction of candidates with Spitzenkandidaten varies considerably across party families. We also identified an incumbency effect, as sitting MEPs interact more horizontally with EP candidates from other countries. This is in line with the idea that learning processes and socialisation in politics have consequences for politicians' behaviour 
and contribute to redefine the way in which candidates communicate on Twitter during campaigns. That MEPs are not more likely to engage in vertical interactions indicates that cultivating relationships with peers might be more important than promoting TNPs or Spitzenkandidaten.

Finally, the findings show that the distinctiveness of EU politicisation is related to the likelihood to engage in the transnational campaign arena, while EU salience measured at the national party level had less of an impact. By nature, EU issues are salient during EP elections, which provides opportunities for political parties to strategically differentiate themselves by capitalizing on or opposing Euroscepticism. In other words, political parties that have clearer pro-or anti-EU positions are more likely to attach more importance to different types of transnational exchanges. Candidates from Europhile parties that put a strong emphasis on the EU embrace the opportunity to engage with actors like TNPs and Spitzenkandidaten vertically. Eurosceptic parties, in contrast, address supranational actors in their Twitter communication sparely and are even more likely to engage horizontally across borders. This reflects a horizontal transnational mobilisation for a 'Europe of nations' by the Eurosceptic radical right but also lively cross-country exchanges of the Eurosceptic left. More generally, our findings suggest that engagement (and interest) in EP campaigns is not only the realm of Europhile actors. In fact, while transnationalisation is often normatively associated with pro-EU orientations, we show that it can also stem from Eurosceptic campaigns. We thus contribute to the literature on politicisation (Hutter and Kriesi 2019; Hutter et al. 2016) by showing that this schism in European politics also affects the nature of transnational political mobilisation.

The empirical insights of this paper could only be gained by studying the interaction patterns revealed by digital behavioural data from Twitter, whereas more established sources in election research do not have the same granularity needed to make inferences with regard to the transnationalisation of political communication - especially not at the level of individual candidates and in a non-intrusive way. It is an important caveat that our methodology does not capture 
interactions that are not channelled through TNPs or Spitzenkandidaten, but through heads of governments or national parties. We have not coded these actors, but the transnational campaign arena can be expanded conceptually and empirically to also comprise a well-defined set of political actors from the national level. While a dictionary analysis showed that tweets with transnational linkages contain a higher share of substantive EU-related content, the next logical step is to conduct a more detailed content analysis, e.g., of whether EU polity or policy discussions stimulate more transnational interactions. Transnational campaign interactions could also be analysed beyond the elite level by taking the engagement of Twitter audiences into account (Fazekas et al. 2020). Moreover, the robustness of the results will have to be tested in longitudinal comparisons and with updated expert judgements on party positions.

Taken together, our findings suggest that further institutional reforms would be needed to overcome the predominant national orientation of EP election campaigns. The fact that the appointment of the President of the Commission in 2019 did not follow the logic of the Spitzenkandidaten system casts doubt on such endeavours. Still, the new President of the European Commission has promised to initiate reforms of the electoral process, trying to bolster the democratic legitimacy of the EU. One prominent suggestion is to promote cross-country candidate lists which - in line with our findings - could indeed further transnationalise EP election campaigns. Future research will have to investigate whether more transnational linkages will help or hurt the process of EU integration in the years to come.

\section{Notes}

1. We acknowledge that the arena can be expanded by including political actors who are primarily oriented towards the national political system (such as heads of government or national parties), regular citizens or media actors who are also engaging with political actors on Twitter.

2. Koopmans and Erbe also identify a supranational dimension related to episodes of public attention devoted to supranational events across EU countries that, however, are not necessarily transnationally linked.

3. Spitzenkandidaten stand somewhere in between the vertical and the horizontal dimension as they are hybrid actors situated in the national and supranational campaign arenas. Still, given their role 
as spearheads for the campaigns of TNPs, we consider them as supranational actors. The empirical findings of the paper are robust to a more restrictive operationalisation (see results section).

4. Except for deleted tweets, which would have to be removed from data sets anyway according to Twitter's terms and conditions.

5. In some cases, parties that formed electoral coalitions for the EP elections (e.g., Podemos and Izquierda Unida in Spain), belonged to different TNPs. We assigned these candidates to the TNPs and the CHES party code of the biggest coalition partner, in the above example, to Podemos.

6. $81 \%$ of all tweets of candidates without a CHES ID were sent by just five parties that were founded only recently and not included in the latest CHES data collection: +Europa, Brexit Party, Change UK, Spring (Poland), and VOX. The rest of the non-covered tweets were sent by independent candidates and smaller parties not covered by CHES.

7. National election results for newly founded parties (e.g., Brexit Party) were coded as 0.

8. There is considerable heterogeneity in the organisation of party lists across European countries, as most countries have nation-wide party lists, whereas some countries such as Italy have regional lists.

9. The uncertainty about the electoral outcome per country is taken into account by calculating the standard deviation between the predictions and the actual seats won for each party. In cases where there were subnational party lists (the CDU/CSU in Germany, Italy, Poland, and the UK), we calculated the electoral viability per candidate based on the share of national EP seats allocated to her/his district. In Finland and Ireland, where there were no ranked party lists, all candidates were categorised as 'doubtful'.

10. We only used original tweets, i.e., removed retweets for this analysis. The keyword list contains translations for strings such as 'ep', 'mep', 'ecb', 'frontex', and the generic string 'europ*'. We removed stop words specific for each language and Twitter handles so that an account name such as @europeangreens does not inflate the measure.

\section{Acknowledgements}

This work was funded by the VolkswagenStiftung under Grant 94758. We thank Swen Hutter, the anonymous reviewers, and participants at the 2019 ECPR General Conference and at the Amsterdam Centre for European Studies Workshop on the European Elections for their valuable comments. Caterina Froio thanks Cyril Benoît for helpful suggestions on related literature. Finally, we are grateful to colleagues across Europe, in particular Michaela Maier, for their help in translating the EU-related keywords and Céline Widera for excellent research assistance.

\section{References}

Adam, Silke, Beatrice Eugster, Eva Antl-Wittenberg, Rachid Azrout, Judith Möller, Claes de Vreese, Michaela Maier, and Sylvia Kritzinger (2019). 'News Media's Position-taking Regarding the European Union: the Synchronization of Mass Media's Reporting and Commentating in the 2014 European Parliament Elections', Journal of European Public Policy, 26:1, 44-62. 
Barberá, Pablo (2015). 'Birds of the Same Feather Tweet Together: Bayesian Ideal Point Estimation Using Twitter Data', Political Analysis, 23:1, 76-91.

Beauvallet, Willy, and Sébastien Michon (2010). 'Professionalization and Socialization of the Members of the European Parliament', French Politics, 8:2, 145-165.

Bennett, W. Lance, Sabine Lang, and Alexandra Segerberg (2014). 'European Issue Publics Online: The Cases of Climate Change and Fair tTade', in Thomas Risse (ed.), European Public Spheres. Cambridge: Cambridge University Press, 108-137.

Bossetta, Michael, Anamaria Dutceac Segesten, and Hans-Jörg Trenz (2017). 'Engaging with European Politics Through Twitter and Facebook: Participation Beyond the National?', in Mauro Barisione and Asimina Michailidou (eds.), Social Media and European Politics: Rethinking Power and Legitimacy in the Digital Era. London: Palgrave Macmillan UK, 53-76.

Brambor, Thomas, William Roberts Clark, and Matt Golder (2006). 'Understanding Interaction Models: Improving Empirical Analyses', Political Analysis, 14:1, 63-82.

Braun, Daniela, and Sebastian A. Popa (2018). 'This Time It Was Different? The Salience of the Spitzenkandidaten System among European Parties', West European Politics, 41:5, $1125-1145$.

Braun, Daniela, and Tobias Schwarzbözl (2019). 'Put in the Spotlight or Largely Ignored? Emphasis on the Spitzenkandidaten by Political Parties in Their Online Campaigns for European Elections', Journal of European Public Policy, 26:3, 428-445.

Christiansen, Thomas (2016). 'After the Spitzenkandidaten: Fundamental change in the EU's Political System?', West European Politics, 39:5, 992-1010.

Conover, Michael et al. (2011). 'Political Polarization on Twitter', in Proceedings of the 5th International AAAI Conference on Web and Social Media. Palo Alto, CA: AAAI Publications, 89-96.

Cotta, Maurizio (1984). 'Direct Elections of the European Parliament: A Supranational Political Elite in the Making?', in Karlheinz Reif (ed.), European Elections 1979/81 and 1984. Berlin: Quorum, 122-126.

Cunningham, Kevin, Simon Hix, Michael Marsh, and Susi Dennison (2019). 'Kingmakers of the Mainstream: Predictions for the European Parliament Election', European Council on Foreign Relations, https://www.ecfr.eu/publications/summary/kingmakers_of_mainstream_predictions_for_european_parliament_election.

Daniel, William T., and Lukas Obholzer (2020). 'Reaching Out to the Voter? Campaigning on Twitter during the 2019 European Elections', Research \& Politics, 7:2 https://doi.org/10.1177/2053168020917256 (Accessed July 13, 2020).

Daniel, William T, Lukas Obholzer, and Steffen Hurka (2017). 'Static and Dynamic Incentives for Twitter Usage in the European Parliament', Party Politics, 135406881774775. 
De Zúñiga, Homero Gil (2015). 'Toward a European Public Sphere? The Promise and Perils of Modern Democracy in the Age of Digital and Social Media', International Journal of Communication, 9, 1: 3152-3160

Döring, Holger, and Philip Manow (2019). 'Parliaments and Governments Database (ParlGov): Information on Parties, Elections and Cabinets in Modern Democracies. Development version'.

Fazekas, Zoltán, Sebastian Adrian Popa, Hermann Schmitt, Pablo Barberá, and Yannis Theocharis (2020). 'Elite-public Interaction on Twitter: EU Issue Expansion in the Campaign', European Journal of Political Research, https://doi.org/10.1111/1475$\underline{6765.12402}$

Froio, Caterina, and Bharath Ganesh (2019). 'The Transnationalisation of Far Right Discourse on Twitter', European Societies, 21:4, 513-539.

Giebler, Heiko, and Bernhard Wessels (2010). '2009 European Election Candidate StudyMethodological Annex', Berlin: WZB, 2009 https://dbk.gesis.org/dbksearch/download.asp?id=37352.

Gilardi, Fabrizio (2010). 'Who Learns from What in Policy Diffusion Processes?', American Journal of Political Science, 54:3, 650-666.

Grande, Edgar, and Hanspeter Kriesi (2014). 'The Restructuring of Political Conflict in Europe and the Politicization of European Integration', in Thomas Risse (ed.), European Public Spheres. Cambridge: Cambridge University Press, 190-224.

Haas, Ernst B (1958). The Uniting of Europe: Political, Social, and Economic Forces, 1950 1957. Stanford, CA: Stanford University Press.

Habermas, Jürgen, and Ciaran Cronin (2012). The Crisis of the European Union: a Response. Cambridge: Polity.

Halikiopoulou, Daphne, Kyriaki Nanou, and Sofia Vasilopoulou (2012). 'The Paradox of Nationalism: The Common Denominator of Radical Right and Radical Left Euroscepticism', European Journal of Political Research, 51:4, 504-539.

Hänska, Max, and Stefan Bauchowitz (2019). 'Can Social Media Dacilitate a European Public Sphere? Transnational Communication and the Europeanization of Twitter During the Eurozone Crisis', Social Media + Society, 5:3.

Hix, Simon, and Michael Marsh (2011). 'Second-order Effects plus Pan-European Political Swings: An Analysis of European Parliament Elections Across Time', Electoral Studies, 30:1, 4-15.

Hobolt, Sara B., and Catherine E. de Vries (2015). 'Issue Entrepreneurship and Multiparty Competition', Comparative Political Studies, 48:9, 1159-1185. 
Hooghe, Liesbet, and Gary Marks (2009). 'A Postfunctionalist Theory of European Integration: From Permissive Consensus to Constraining Dissensus', British Journal of Political Science, 39:1, 1-23.

Hutter, Swen, and Edgar Grande (2014). 'Politicizing Europe in the National Electoral Arena: A Comparative Analysis of Five West European Countries, 1970-2010', JCMS: Journal of Common Market Studies, 52:5, 1002-1018.

Hutter, Swen, Edgar Grande, and Hanspeter Kriesi, eds. (2016). Politicising Europe: Integration and Mass Politics. Cambridge: Cambridge University Press.

Hutter, Swen, and Hanspeter Kriesi (2019). 'Politicizing Europe in Times of Crisis', Journal of European Public Policy, 26:7, 996-1017T

Kielmansegg, Peter Graf (2003). 'Integration und Demokratie', in Markus Jachtenfuchs and Beate Kohler-Koch (eds.), Europäische Integration. Wiesbaden: VS Verlag für Sozialwissenschaften, 49-76.

Koopmans, Ruud, and Jessica Erbe (2004). 'Towards a European Public Sphere?', Innovation: The European Journal of Social Science Research, 17:2, 97-118.

Laffan, Brigid (2016). 'Europe's Union in Crisis: Tested and Contested', West European Politics, 39:5, 915-932.

Larsson, Anders Olof (2015). 'The EU Parliament on Twitter - Assessing the Permanent Online Practices of Parliamentarians', Journal of Information Technology \& Politics, 12:2, 149-166.

Lilleker, Darren G., and Karolina Koc-Michalska (2013). 'Online Political Communication Strategies: MEPs, E-Representation, and Self-Representation', Journal of Information Technology \& Politics, 10:2, 190-207.

Maier, Michaela, Jesper Strömbäck, and Lynda Lee Kaid (2016). Political Communication in European Parliamentary Elections. London: Routledge.

McDonnell, Duncan, and Annika Werner (2019). International Populism: The Radical Right in the European Parliament. London: C Hurst \& Co.

Murthy, Dhiraj (2012). 'Towards a Sociological Understanding of Social Media: Theorizing Twitter', Sociology, 46:6, 1059-1073.

Nulty, Paul, Yannis Theocharis, Sebastian Adrian Popa, Olivier Parnet, and Kenneth Benoit (2016). 'Social Media and Political Communication in the 2014 Elections to the European Parliament', Electoral Studies, 44, 429-444.

Obholzer, Lukas, and William T Daniel (2016). 'An Online Electoral Connection? How eEectoral Systems Condition Representatives' Social Media Use', European Union Politics, $17: 3,387-407$. 
Pirro, Andrea Lp, Paul Taggart, and Stijn Van Kessel (2018). 'The Populist Politics of Euroscepticism in Times of Crisis: Comparative Conclusions', Politics, 38:3, 378-390.

Polk, Jonathan et al. (2017). 'Explaining the Salience of Anti-elitism and Reducing Political Corruption for Political Parties in Europe with the 2014 Chapel Hill Expert Survey Data', Research \& Politics, 4:1.

Popa, Sebastian Adrian, Zoltán Fazekas, Daniela Braun, and Melanie-Marita Leidecker-Sandmann (2020). 'Informing the Public: How Party Communication Builds Opportunity Structures', Political Communication, 37:3, 329-349.

Reif, Karlheinz, and Hermann Schmitt (1980). 'Nine Second-order National Elections - A Conceptual Framework for the Analysis of European Election Results', European Journal of Political Research, 8:1, 3-44.

Risse, Thomas (2014a). 'European Public spheres, the Politicization of EU Affairs, and Its Consequences', in Thomas Risse (ed.), European Public Spheres. Cambridge: Cambridge University Press, 141-164.

Risse, Thomas (2014b). 'Introduction', in Thomas Risse (ed.), European Public Spheres. Cambridge: Cambridge University Press, 1-26.

Ruiz-Soler, Javier, Luigi Curini, and Andrea Ceron (2019). 'Commenting on Political Topics Through Twitter: Is European Politics European?', Social Media + Society, 5:4, 205630511989088.

Schmidt, Vivien A. (2019). 'Politicization in the EU: Between National Politics and EU Political Dynamics', Journal of European Public Policy, 26:7, 1018-1036.

Schmitt, Hermann (2005). 'The European Parliament Elections of June 2004: Still Second-Order?', West European Politics, 28:3, 650-679.

Schmitt, Hermann, Sara Hobolt, and Sebastian Adrian Popa (2015). 'Does Personalization Increase Turnout? Spitzenkandidaten in the 2014 European Parliament Elections', European Union Politics, 16:3, 347-368.

Scully, Roger (2005). Becoming Europeans? Oxford: Oxford University Press http://www.oxfordscholarship.com/view/10.1093/0199284326.001.0001/acprof-9780199284320 (Accessed May 22, 2020).

Smith, Julie (1995). 'Appendix. The 1994 European Elections: Twelve Into One Won't Go', West European Politics, 18:3, 199-217.

Spoon, Jae-Jae (2012). 'How Salient is Europe? An analysis of European Election Manifestos, 1979-2004', European Union Politics, 13:4, 558-579.

Statham, Paul, and Hans-Jörg Trenz (2015). 'Understanding the Mechanisms of EU Politicization: Lessons from the Eurozone Crisis', Comparative European Politics, 13:3, 287306. 
Stier, Sebastian, Arnim Bleier, Haiko Lietz, and Markus Strohmaier (2018a). 'Election Campaigning on Social Media: Politicians, Audiences and the Mediation of Political Communication on Facebook and Twitter', Political Communication, 35:1, 50-74.

Stier, Sebastian, Sebastian A. Popa, and Daniela Braun (2020). 'Political Campaigning on Twitter During the 2019 European Parliament Election Campaign', GESIS Data Archive, https://doi.org/10.7802/1.1995

Stier, Sebastian, Wolf J Schünemann, and Stefan Steiger (2018b). 'Of Activists and Gatekeepers: Temporal and Structural Properties of Policy Networks on Twitter', New Media \& Society, 20:5, 1910-1930.

Theocharis, Yannis, Pablo Barberá, Zoltán Fazekas, Sebastian Adrian Popa, and Olivier Parnet (2016). 'A Bad Workman Blames His Tweets: The Consequences of Citizens' Uncivil Twitter Use When Interacting With Party Candidates: Incivility in Interactions With Candidates on Twitter', Journal of Communication, 66:6, 1007-1031.

Van Hauwaert, Steven M. (2019). 'On Far Right Parties, Master Frames and Trans-national Diffusion: Understanding Far Right Party Development in Western Europe', Comparative European Politics, 17:1, 132-154.

Weber, Till (2007). 'Campaign Effects and Second-Order Cycles', European Union Politics, $8: 4,509-536$.

Zürn, Michael (2019). 'Politicization Compared: at National, European, and Global Levels', Journal of European Public Policy, 26:7, 977-995.

\section{Notes on contributors}

Sebastian Stier is a Senior Researcher at the Department Computational Social Science of GESIS - Leibniz Institute for the Social Sciences in Cologne. His research focuses on political communication, comparative politics, party politics, and the use of digital trace data and computational methods in the social sciences. [sebastian.stier@gesis.org]

Caterina Froio is Assistant Professor in Political Science at Sciences Po (CEE). Her research interests are broadly in European politics, with a special emphasis on political parties, e-politics, right-wing extremism, radicalism and populism. Since 2016 she is joint convenor of the European Consortium for Political Research (ECPR) Standing Group on Extremism \& Democracy. [caterina.froio@sciencespo.fr] 
Wolf J. Schünemann is Assistant Professor at the Institute of Social Sciences at Hildesheim University. His research focuses on European politics, digital governance and communication, discourse research including computational methods. [wolf.schuenemann@uni-hildesheim.de] 


\title{
'Going transnational? Candidates' transnational linkages on Twitter during the 2019 European Parliament elections' OnLine Appendix
}

\author{
Sebastian Stier, Caterina Froio, and Wolf J. Schünemann
}

\section{Contents}

1 Description of the Twitter data 2

2 Construction of the politicisation measure $\quad 5$

$\begin{array}{lll}3 & \text { Descriptive statistics } & 7\end{array}$

4 Alternative conceptualisation of Spitzenkandidaten linkages $\quad 9$

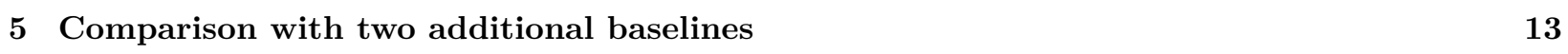

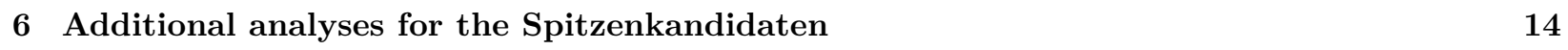

7 References $\quad 16$ 


\section{Description of the Twitter data}

Table A1 shows the number of included parties (or electoral coalitions) and EP candidates by country. The statistics here are based on the same selection criteria used in the main text, i.e., we excluded the accounts of EU Spitzenkandidaten and EU TNPs from the list of senders. 3,070 EP candidates sent at least one tweet during our research period between 23 April and 30 May 2019 (column \% Active). Table A2 shows the same statistics grouped by European TNPs.

Table A1: EP candidates by country.

\begin{tabular}{lrrrr}
\hline Country & Parties & Candidates & \% Active & Tweets \\
\hline Austria & 5 & 101 & 41.58 & 8,679 \\
Belgium & 13 & 216 & 48.61 & 19,956 \\
Bulgaria & 5 & 85 & 17.65 & 620 \\
Croatia & 12 & 144 & 22.92 & 3,389 \\
Cyprus & 5 & 30 & 33.33 & 303 \\
Czech Republic & 8 & 215 & 23.72 & 2,756 \\
Denmark & 10 & 135 & 51.11 & 6,036 \\
Estonia & 6 & 54 & 42.59 & 731 \\
Finland & 8 & 160 & 73.75 & 11,260 \\
France & 6 & 474 & 68.78 & 69,541 \\
Germany & 7 & 602 & 29.90 & 14,732 \\
Greece & 6 & 233 & 22.32 & 5,384 \\
Hungary & 7 & 222 & 18.47 & 1,226 \\
Ireland & 8 & 51 & 74.51 & 15,645 \\
Italy & 6 & 433 & 55.43 & 20,597 \\
Latvia & 9 & 144 & 45.83 & 5,171 \\
Lithuania & 13 & 249 & 6.83 & 179 \\
Luxembourg & 8 & 48 & 41.67 & 802 \\
Malta & 5 & 33 & 60.61 & 1,657 \\
Netherlands & 11 & 234 & 72.22 & 17,276 \\
Poland & 5 & 650 & 44.00 & 49,928 \\
Portugal & 6 & 162 & 19.14 & 6,561 \\
Romania & 7 & 269 & 10.78 & 662 \\
Slovakia & 13 & 178 & 6.74 & 170 \\
Slovenia & 9 & 71 & 45.07 & 5,144 \\
Spain & 8 & 430 & 57.44 & 83,525 \\
Sweden & 8 & 326 & 50.61 & 20,092 \\
United Kingdom & 9 & 523 & 69.22 & 144,329 \\
\hline & & & &
\end{tabular}

Table A2: EP candidates by European TNP.

\begin{tabular}{lrrrr}
\hline European TNP & Parties & Candidates & \% Active & Tweets \\
\hline ACRE & 12 & 467 & 49.68 & 40,411 \\
ALDE & 31 & 901 & 44.17 & 54,724 \\
EFA & 5 & 115 & 40.87 & 24,648 \\
EGP & 13 & 363 & 62.53 & 60,932 \\
EPP & 42 & 1,330 & 38.65 & 59,263 \\
MENF & 7 & 220 & 54.09 & 19,627 \\
Now the People & 3 & 171 & 67.84 & 30,663 \\
PEL & 8 & 154 & 29.22 & 6,731 \\
PES & 28 & 852 & 47.89 & 72,082 \\
Others & 72 & 1,899 & 36.49 & 147,270 \\
\hline
\end{tabular}


Figure A1 displays the temporal distribution of tweets by candidates for the European Parliament. Activity increases with election day approaching. There was also slightly more activity on the day of the European Broadcasting Union (EBU) televised Spitzenkandidaten debate (15 May 2019).

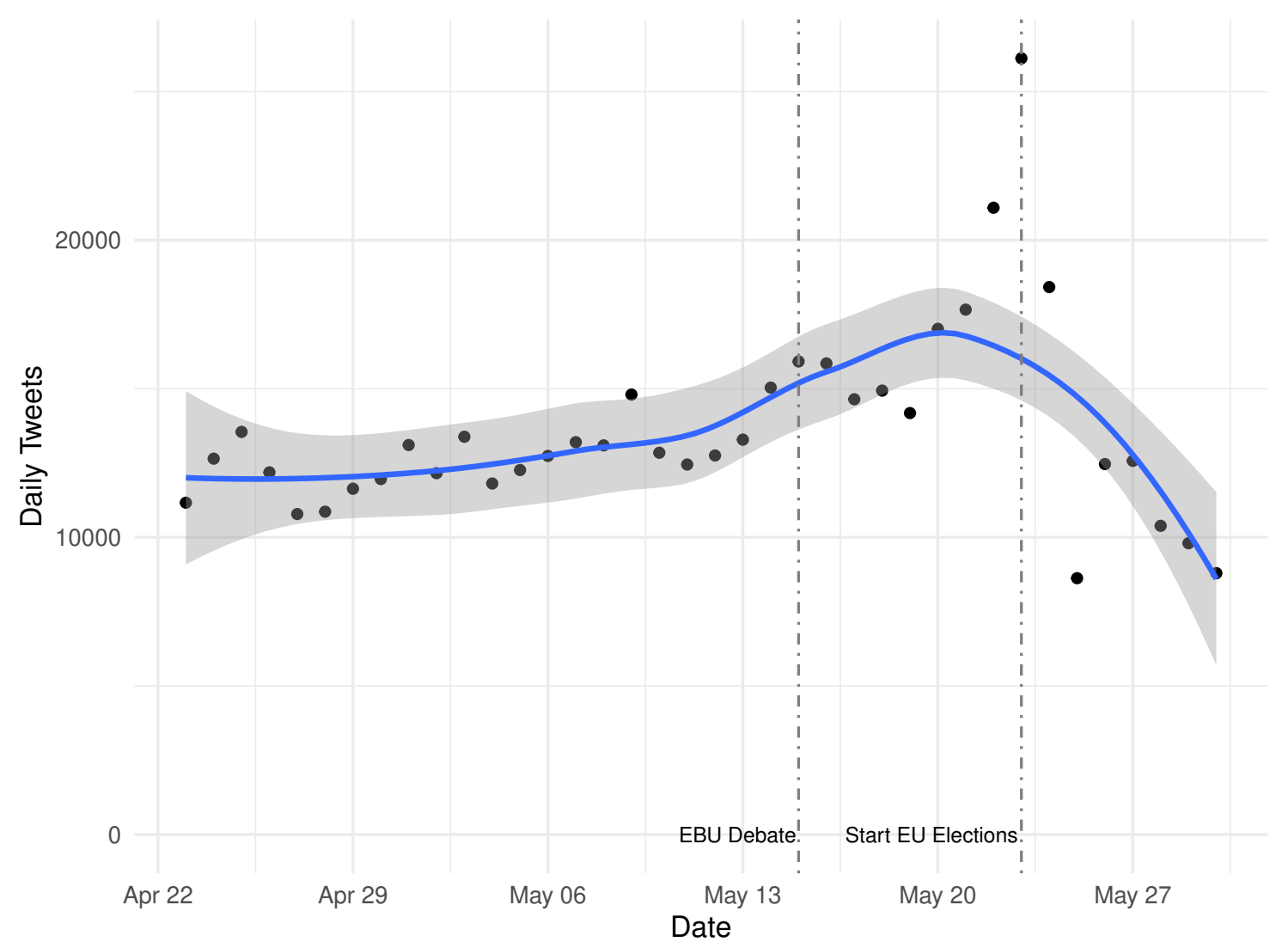

Figure A1: Temporal distribution of tweets by EP candidates. 
In order to illustrate our measurement of communicative linkages, we list here the top 15 targets that are most frequently referenced in EP candidates' tweets. We restricted the targets to the actors of interest in the paper, i.e., EP campaign elite actors (EU Spitzenkandidaten, EU TNPs or EP candidates) that are most often @-mentioned (Table A3) and retweeted by EP candidates (Table A4). We also included the share of linkages that are coming from the same TNP. There is considerable heterogeneity, especially in @-mentions, which indicates that the operationalisation of linkages picks up a variety of different (negative and positive) signals.

Table A3: EP campaign elite actors most often @-mentioned by EP candidates.

\begin{tabular}{llrr}
\hline Actor & Type & @-mentions & In-TNP share \\
\hline Aubry, Manon & EP Candidate & 1,030 & 0.96 \\
Farage, Nigel & EP Candidate & 853 & 0.84 \\
Biedroń, Robert & EP Candidate & 631 & 0.85 \\
Bellamy, François-Xavier & EP Candidate & 627 & 0.85 \\
Loiseau, Nathalie & EP Candidate & 614 & 0.45 \\
Salvini, Matteo & EP Candidate & 571 & 0.58 \\
Bardella, Jordan & EP Candidate & 567 & 0.92 \\
Timmermans, Frans & Spitzenkandidat & 530 & 0.73 \\
Jadot, Yannick & EP Candidate & 501 & 0.85 \\
Le Pen, Marine & EP Candidate & 466 & 0.84 \\
Glucksmann, Raphaël & EP Candidate & 464 & 0.90 \\
PES & TNP & 423 & 0.94 \\
Weber, Manfred & Spitzenkandidat & 409 & 0.56 \\
Magid, Magid & EP Candidate & 399 & 0.94 \\
Adonis, Lord Andrew & EP Candidate & 398 & 0.18 \\
\hline
\end{tabular}

Table A4: EP campaign elite actors most often retweeted by EP candidates.

\begin{tabular}{llrr}
\hline Actor & Type & Retweets & In-TNP share \\
\hline Jadot, Yannick & EP Candidate & 1,097 & 1.00 \\
Aubry, Manon & EP Candidate & 919 & 1.00 \\
Le Pen, Marine & EP Candidate & 891 & 1.00 \\
Bardella, Jordan & EP Candidate & 845 & 1.00 \\
Boye, Gonzalo & EP Candidate & 662 & 0.95 \\
Greens & TNP & 600 & 0.89 \\
Biedroń, Robert & EP Candidate & 537 & 1.00 \\
Andrieu, Éric & EP Candidate & 503 & 1.00 \\
Cormand, David & EP Candidate & 490 & 1.00 \\
Camargo, Eduard Aleix Sarri & EP Candidate & 411 & 0.95 \\
Farage, Nigel & EP Candidate & 388 & 0.97 \\
Verhofstadt, Guy & Spitzenkandidat & 381 & 0.75 \\
PES & TNP & 380 & 0.85 \\
Bellamy, François-Xavier & EP Candidate & 376 & 1.00 \\
Glucksmann, Raphaël & EP Candidate & 372 & 1.00 \\
\hline
\end{tabular}




\section{Construction of the politicisation measure}

Previous literature has conceptualised politicisation as a multiplicative variable of EU Salience and EU Polarisation (Hutter and Kriesi 2019). Figure A2 plots the position of parties across these two dimensions. It becomes clear that parties that put a stronger focus on the EU also have more polarised, i.e., more positive or negative positions on European integration. The British UKIP and Liberal Democrats are illustrative examples for such polarised parties. In contrast, the Greek Golden Dawn party (in the top left corner) has a very negative position on European integration, but de-emphasises the EU.

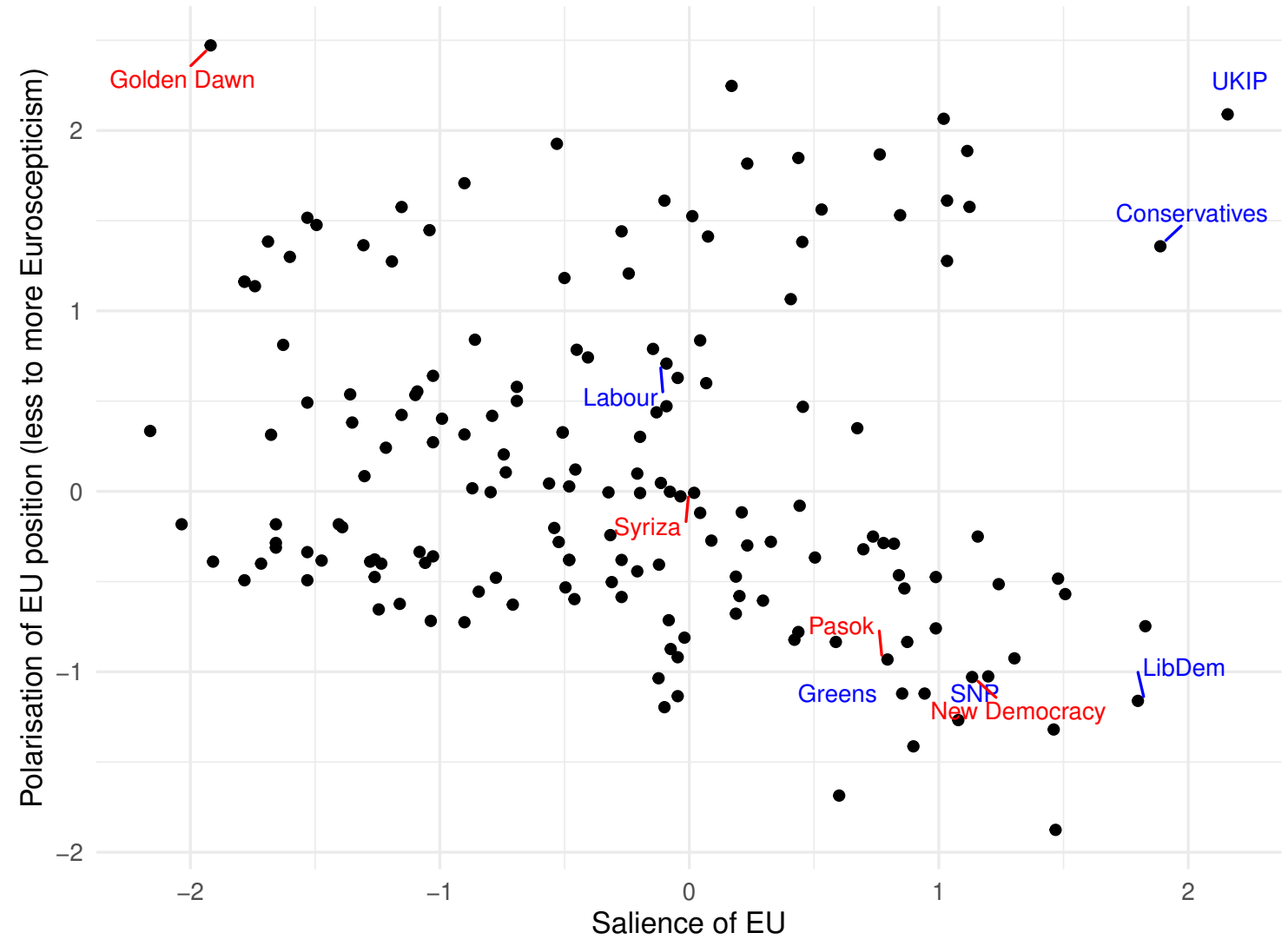

Figure A2: Politicisation at the party level, based on the most recent CHES expert assessments. Red = Greek parties, Blue $=$ UK parties. 
Figure A3 shows the mean values of TNPs across the same value range. Parties from the populist radical right Movement for a Europe of Nations and Freedom (MENF) politicise Europe the most.

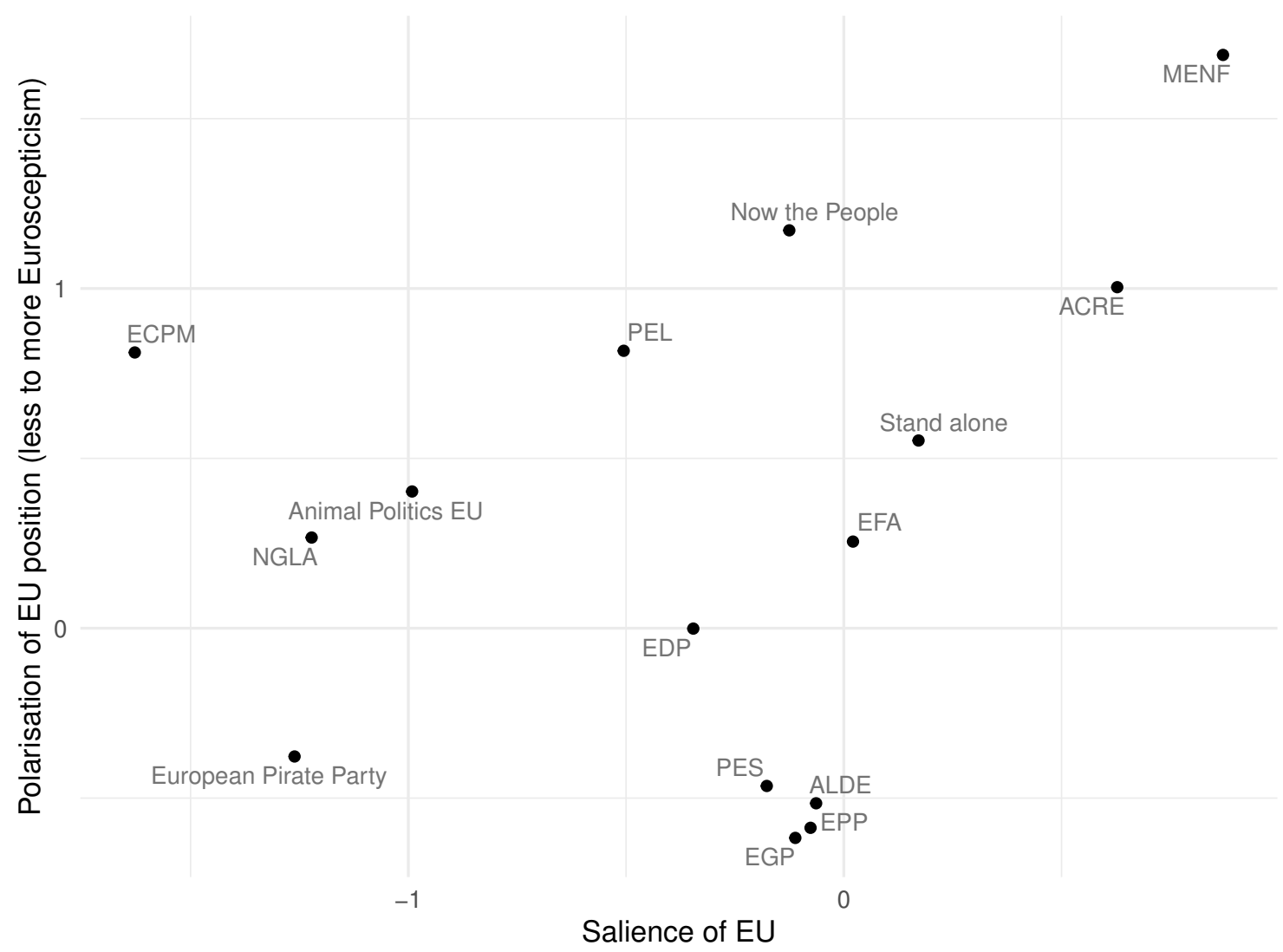

Figure A3: Politicisation at the level of Transnational Parties (TNPs), based on the most recent CHES expert assessments. 


\section{Descriptive statistics}

Descriptive statistics for the main dependent, independent and control variables are shown in Table A5. Figure A4 visualises the correlations between the variables used in the regression models.

Table A5: Descriptive statistics for the variables used.

\begin{tabular}{lcccccc}
\hline \hline Statistic & $\mathrm{N}$ & Mean & Median & St. Dev. & Min & Max \\
\hline National & 2,799 & 26.77 & 6 & 60.51 & 0 & 1,059 \\
Transnational, horizontal & 2,799 & 0.77 & 0 & 4.41 & 0 & 131 \\
Transnational, vertical & 2,799 & 2.13 & 0 & 6.59 & 0 & 93 \\
TNP has Spitzenkandidat & 2,799 & 0.65 & 1 & 0.48 & 0 & 1 \\
EU polarisation & 2,435 & 0.00 & -0.20 & 1.00 & -1.88 & 2.47 \\
EU salience & 2,435 & 0.00 & -0.05 & 1.00 & -2.16 & 2.16 \\
EU polarisation X EU salience & 2,435 & -0.09 & -0.01 & 1.14 & -4.74 & 4.51 \\
Ideology (left/right) & 2,435 & 5.46 & 5.56 & 2.35 & 0.40 & 9.92 \\
National vote share & 2,799 & 13.86 & 10.70 & 11.95 & 0.00 & 55.04 \\
National government participation & 2,799 & 0.27 & 0 & 0.45 & 0 & 1 \\
(Sub)national lead candidate & 2,799 & 0.09 & 0 & 0.29 & 0 & 1 \\
Total tweets sent (original scale) & 2,799 & 184.48 & 72 & 397.27 & 1 & 9,487 \\
Total tweets sent (logged) & 2,799 & 4.05 & 4.28 & 1.71 & 0.00 & 9.16 \\
Incumbent & 2,799 & 0.10 & 0 & 0.30 & 0 & 1 \\
Male & 2,799 & 0.58 & 1 & 0.49 & 0 & 1 \\
Viability: doubtful & 2,799 & 0.15 & 0 & 0.36 & 0 & 1 \\
Viability: safe & 2,799 & 0.09 & 0 & 0.29 & 0 & 1 \\
Viability: unpromising & 2,799 & 0.76 & 1 & 0.43 & 0 & 1 \\
\hline
\end{tabular}

Statistics are only shown for candidates who were active on Twitter during the EP campaign $(N=2,799)$. 


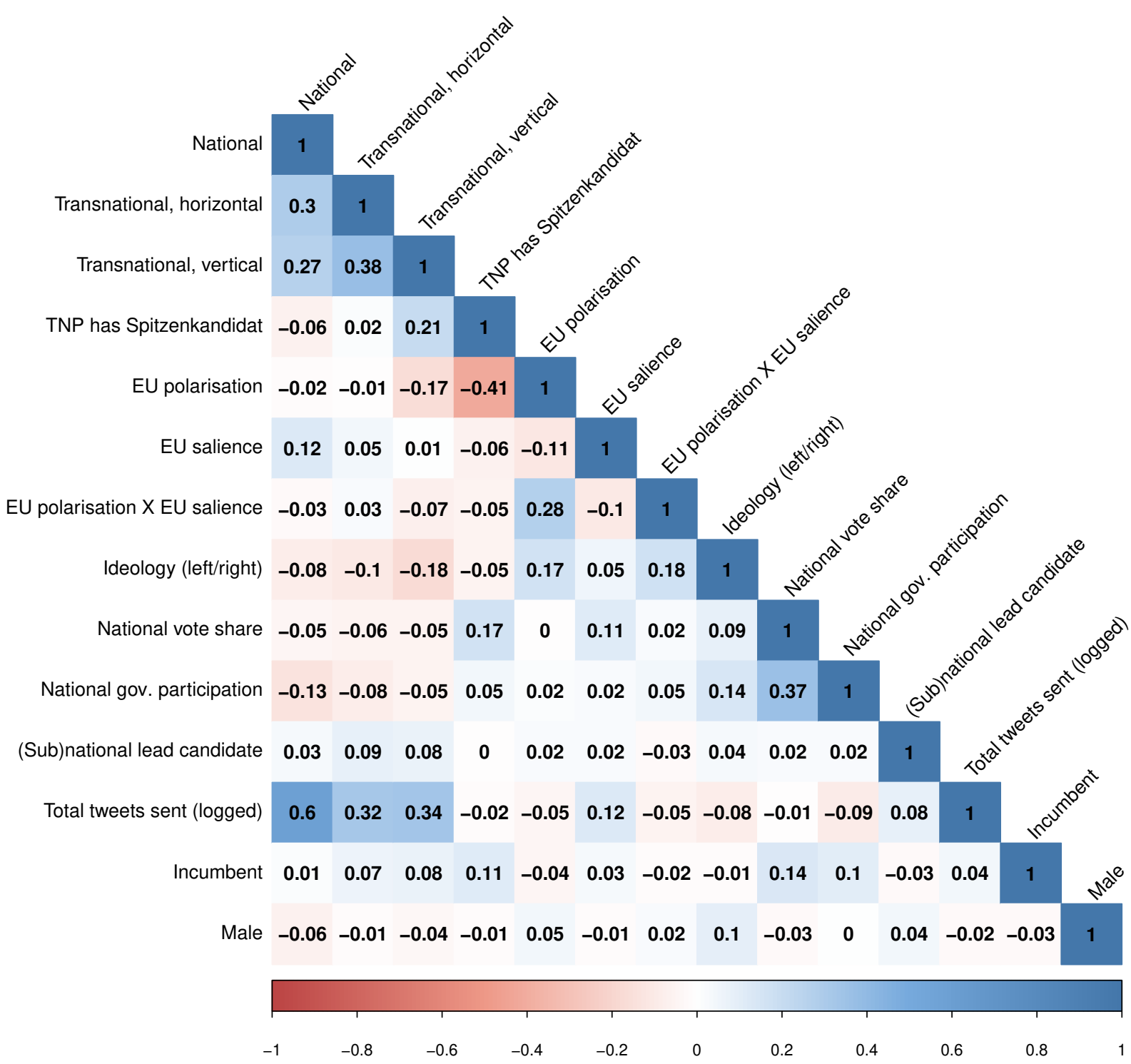

Figure A4: Correlation matrix (Kendall's $\tau$ ). Data from candidates who were active on Twitter during the EP campaign $(N=2,799)$. 


\section{Alternative conceptualisation of Spitzenkandidaten linkages}

In the main paper, we assigned linkages to a Spitzenkandidat by an EP candidate from her or his own country as a vertical transnational linkage. While the lead candidates are supranational actors by institutional design, it can be assumed that linkages to their accounts also refer to their national roles as local or national lead candidates (e.g., Manfred Weber from the EPP).

In the following, we replicate all analyses from the main paper with an alternative conceptualisation: all linkages to a Spitzenkandidat from his or her country are counted as national linkages, thereby reducing the total amount of vertical transnational communicative linkages. This is reflected in the descriptive plots (Figure A5, Figure A6 and Figure A7). The main regression results still hold (Table A6, Figure A8).

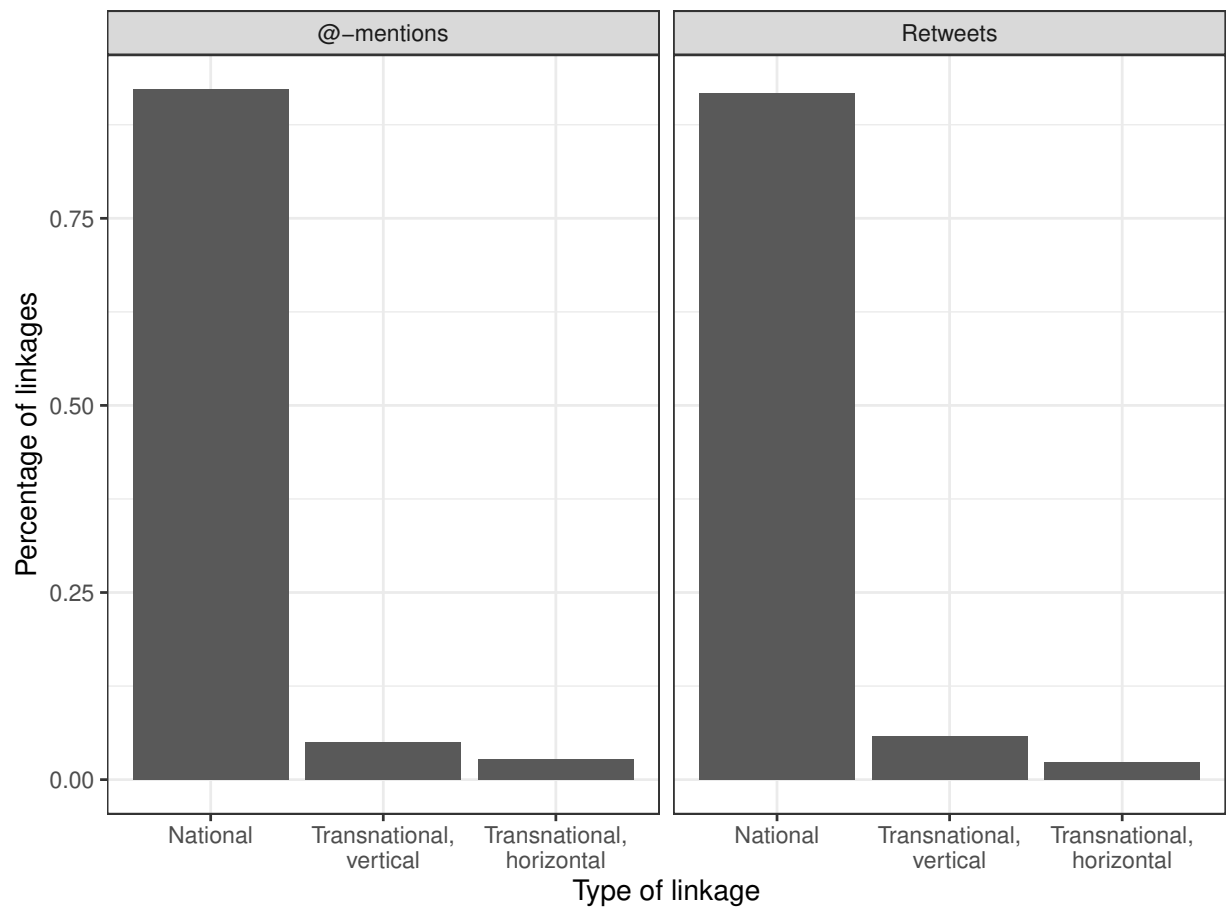

Figure A5: Types of communicative linkages in tweets by EP candidates. Alternative conceptualisation of Spitzenkandidaten linkages. 


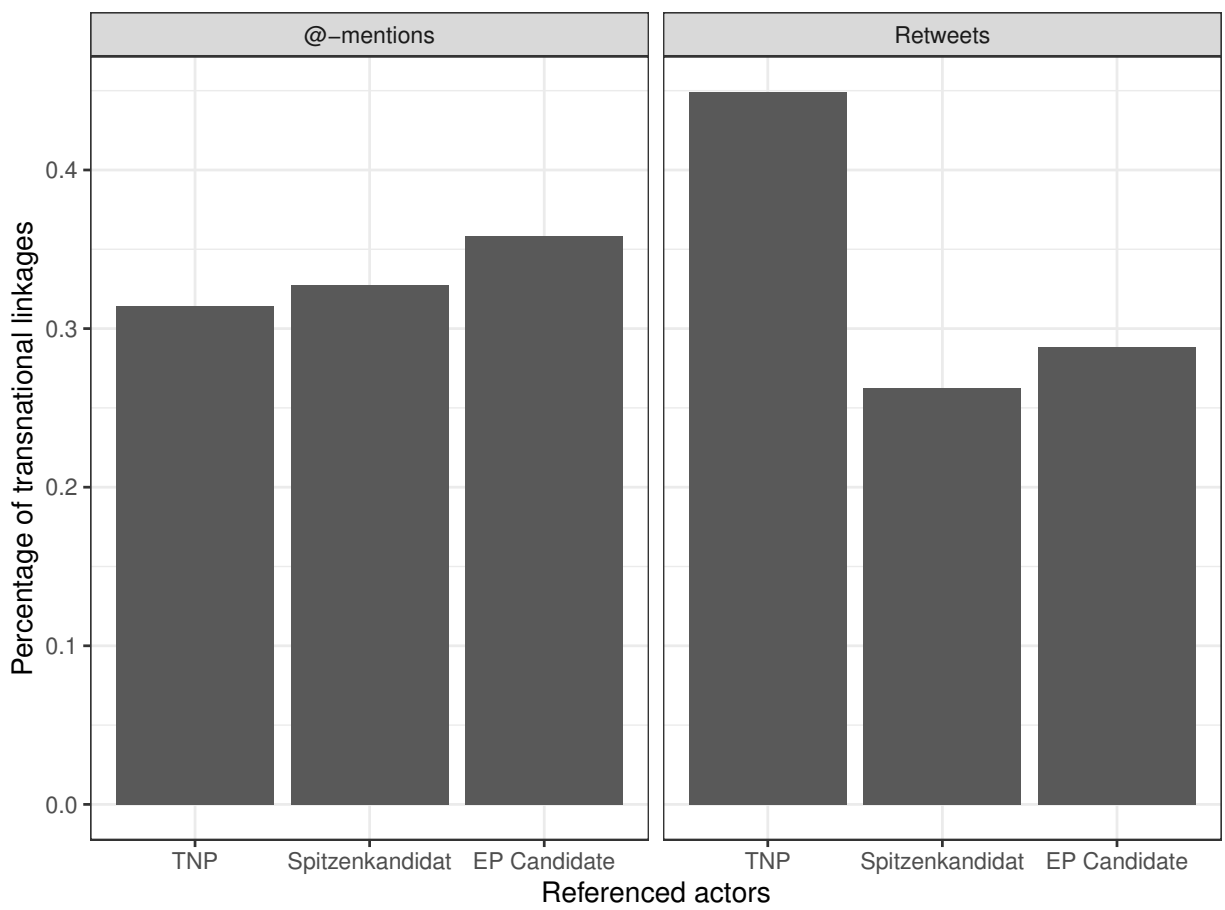

Figure A6: Types of transnational communicative linkages in tweets by EP candidates. Alternative conceptualisation of Spitzenkandidaten linkages.
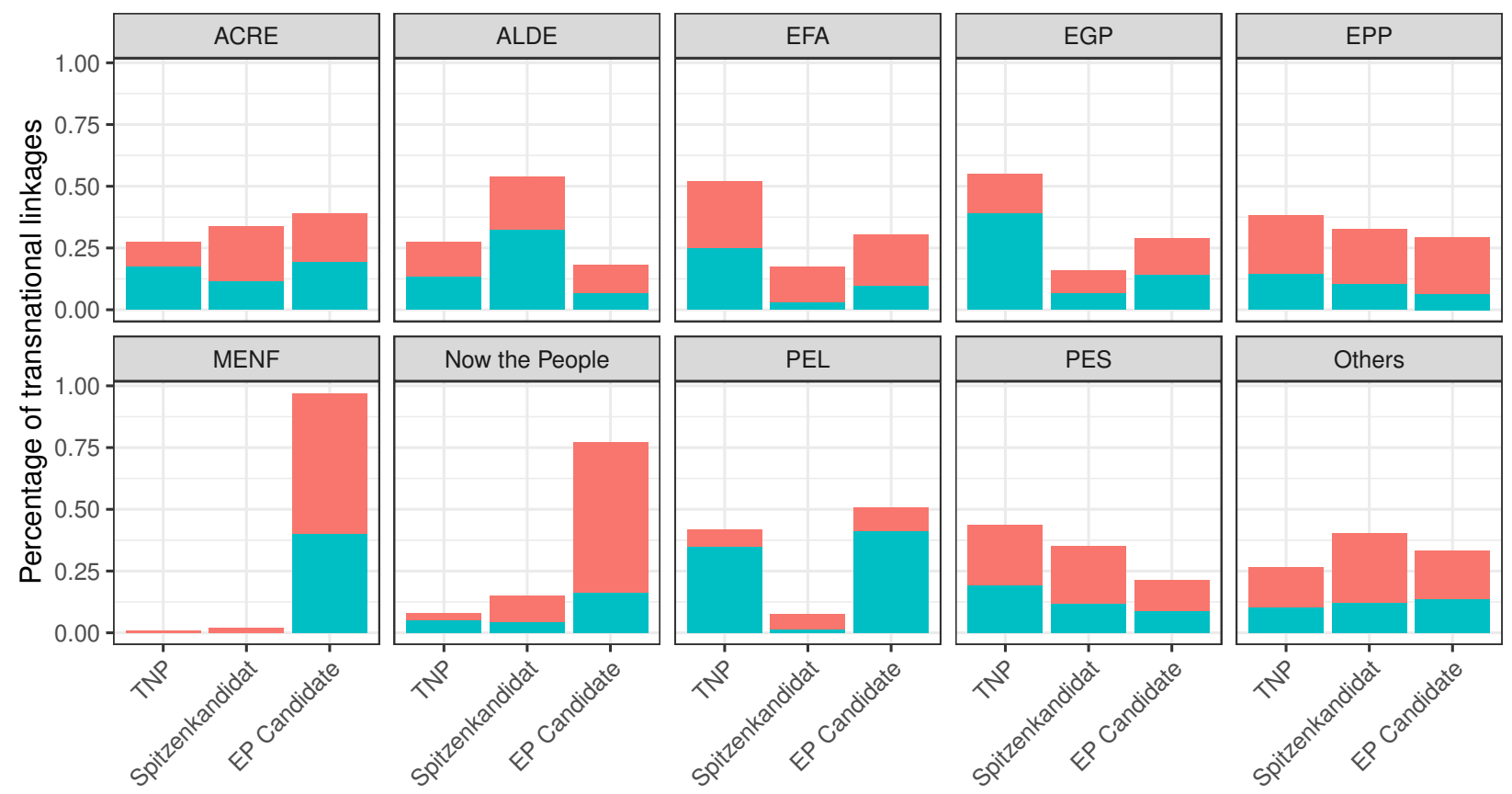

Referenced actors

@-mentions

Retweets

Figure A7: Types of transnational communicative linkages in tweets by EP candidates, aggregated by TNP. Alternative conceptualisation of Spitzenkandidaten linkages. 
Table A6: Hierarchical models with 2 levels, alternative conceptualisation of Spitzenkandidaten linkages.

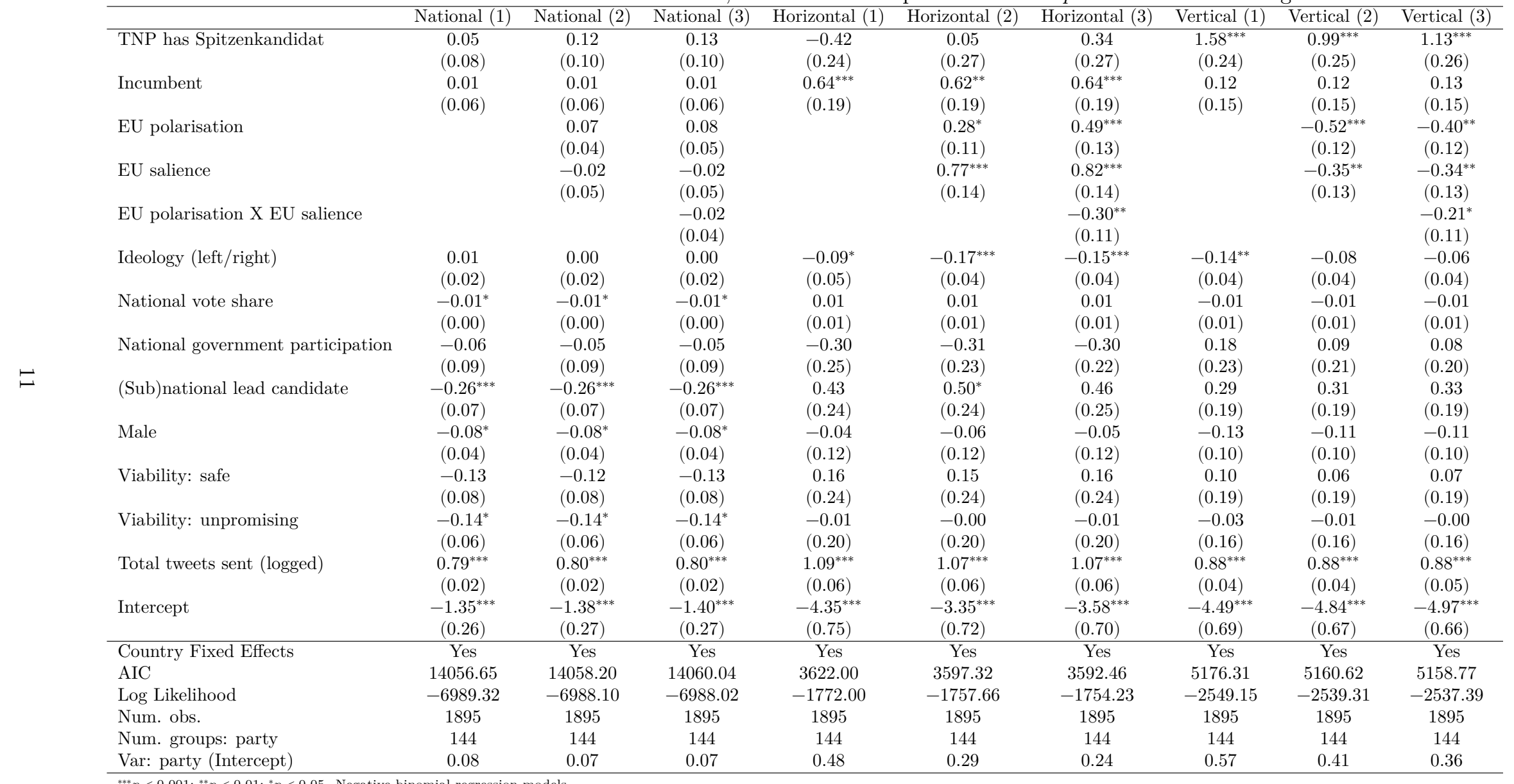



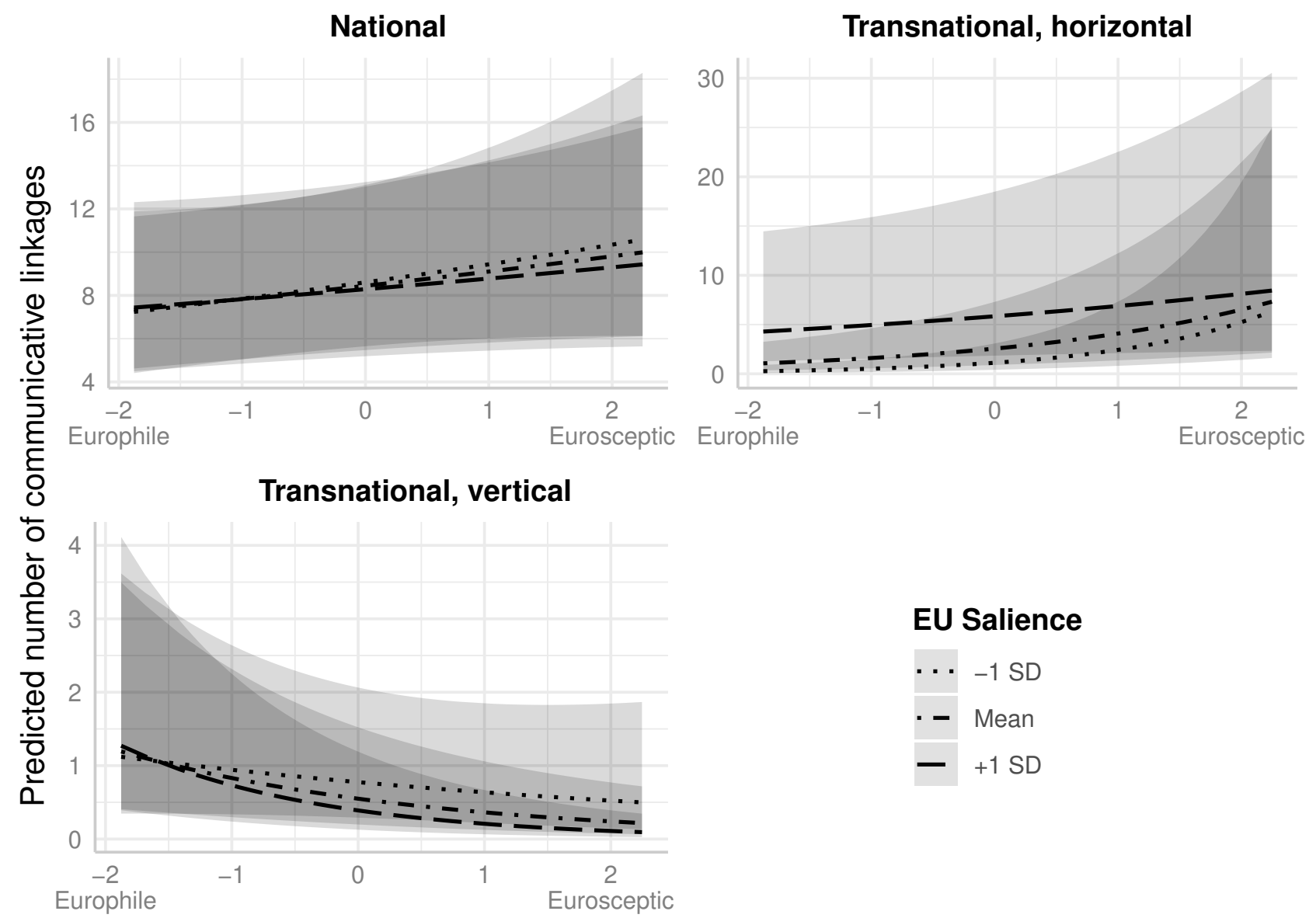

\section{EU Salience}

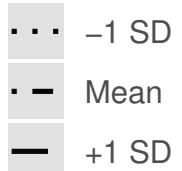

\section{EU Polarisation}

Figure A8: Predicted number of linkages for the interaction EU polarisation $X$ EU salience. Marginal effects including $95 \%$ confidence intervals are shown for the mean, one standard deviation below and above the mean value of EU Salience. Output from the respective Models 3 in Table A6. 


\section{Comparison with two additional baselines}

As the first additional baseline, we researched each national party's main Twitter account, allowing us to introduce linkages to the main points of reference in the national party system as a baseline representing the domestic political arena.

Tweets sent by the same set of EP candidates after the campaign serve as the second additional baseline. We collected the last 3,200 tweets (the maximum available) by all EP candidates from the Twitter REST API using the $\mathrm{R}$ package rtweet (Kearney 2019). The dataset comprises 1,217,552 tweets sent by 2,743 candidates (compared to 2,799 candidates who tweeted during the EP campaign) during the research period of 1 July 2019 (the constitution of the Ninth EP session) to 28 February $2020 .{ }^{1}$ We reran the methodology applied in the main paper and also included the national accounts identified as the first baseline.

Compared to main results for the EP campaign, Figure A9 reveals considerable stability, but higher shares of horizontal linkages at the expense of national linkages.

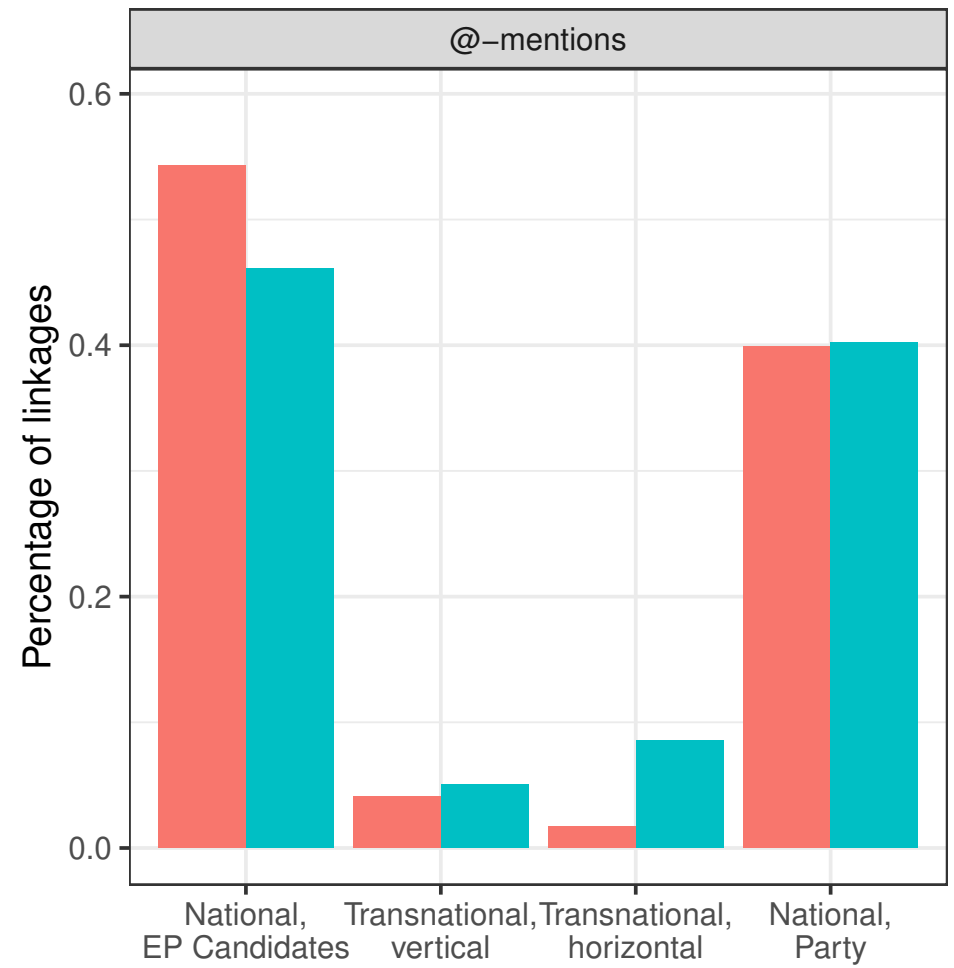

Type of linkage

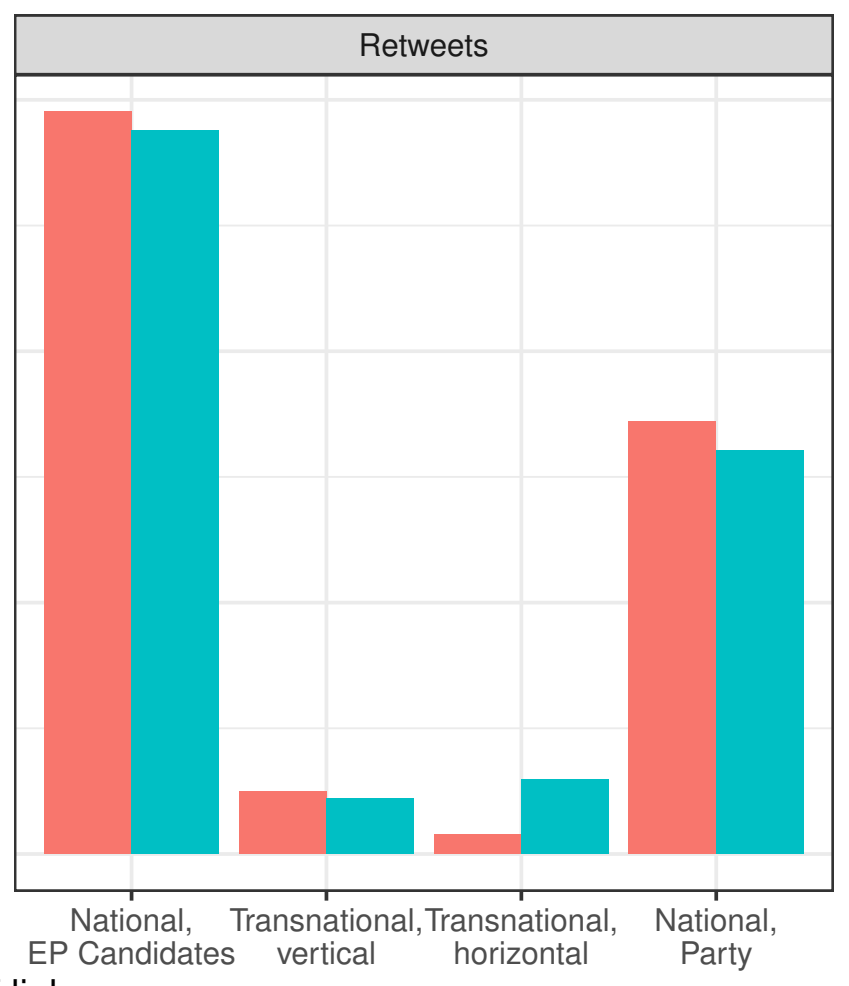

National, Transnational,Transnational, National, P Candidates vertical horizontal Party

\section{Time period Campaign Non-campaign}

Figure A9: Types of communicative linkages in tweets by EP candidates during campaign and non-campaign period. References to Twitter accounts of national parties included as a baseline.

\footnotetext{
${ }^{1}$ The research period was terminated before the COVID-19 pandemic dominated politics in European member states and the EU.
} 


\section{Additional analyses for the Spitzenkandidaten}

We searched for free text mentions of the Spitzenkandidaten ("weber", "timmermans", etc.) in the tweets sent by EP candidates (excluding retweets). Unsurprisingly, the number of @-mentions and string mentions of each Spitzenkandidat are highly correlated (Kendall's $\tau$ rank correlations $=0.86$ ), as most candidate Twitter handles include the names used in the string search (e.g., @ManfredWeber contains "weber"). Yet the close correspondence of the two measures for each candidate in Figure A10 demonstrates that there are no systematic deviations for specific Spitzenkandidaten. However, despite the rather unique names, there are considerable amounts of false positives such as @fabienne_keller (another EP candidate), @Beeron1030 (another user) or "(drinking) beer". We even had to remove the European Left Spitzenkandidat Nico Cué since this string had too many overlaps with the regular vocabulary in various languages. A string search including the names of all 6,500 candidates (smith, müller, etc.) would therefore be very imprecise and result in a large number of false positives.

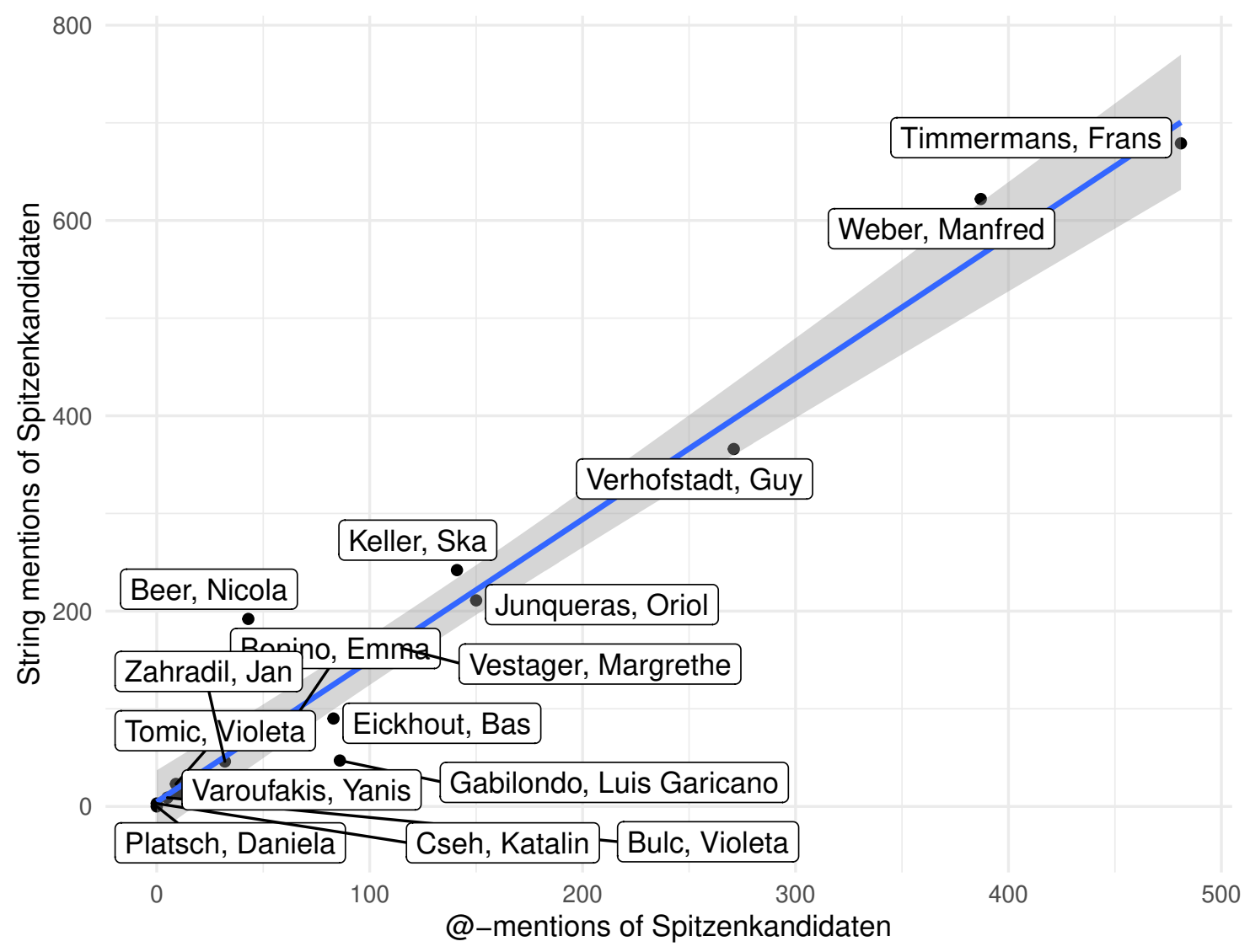

Figure A10: Comparison of @-mentions and free text mentions of Spitzenkandidaten. 
The Spitzenkandidaten were distributed unequally across member states. It is therefore interesting to see whether this resulted in a core-periphery divide that might have influenced the transnational dynamics of the EP campaign. However, Figure A11 shows that there is no readily apparent relationship between the share of linkages in tweets and seats in the EP by country. Among the two countries with the most prominent Spitzenkandidaten, Germany is the outlier, while in contrast, the Netherlands does not particularly stand out.

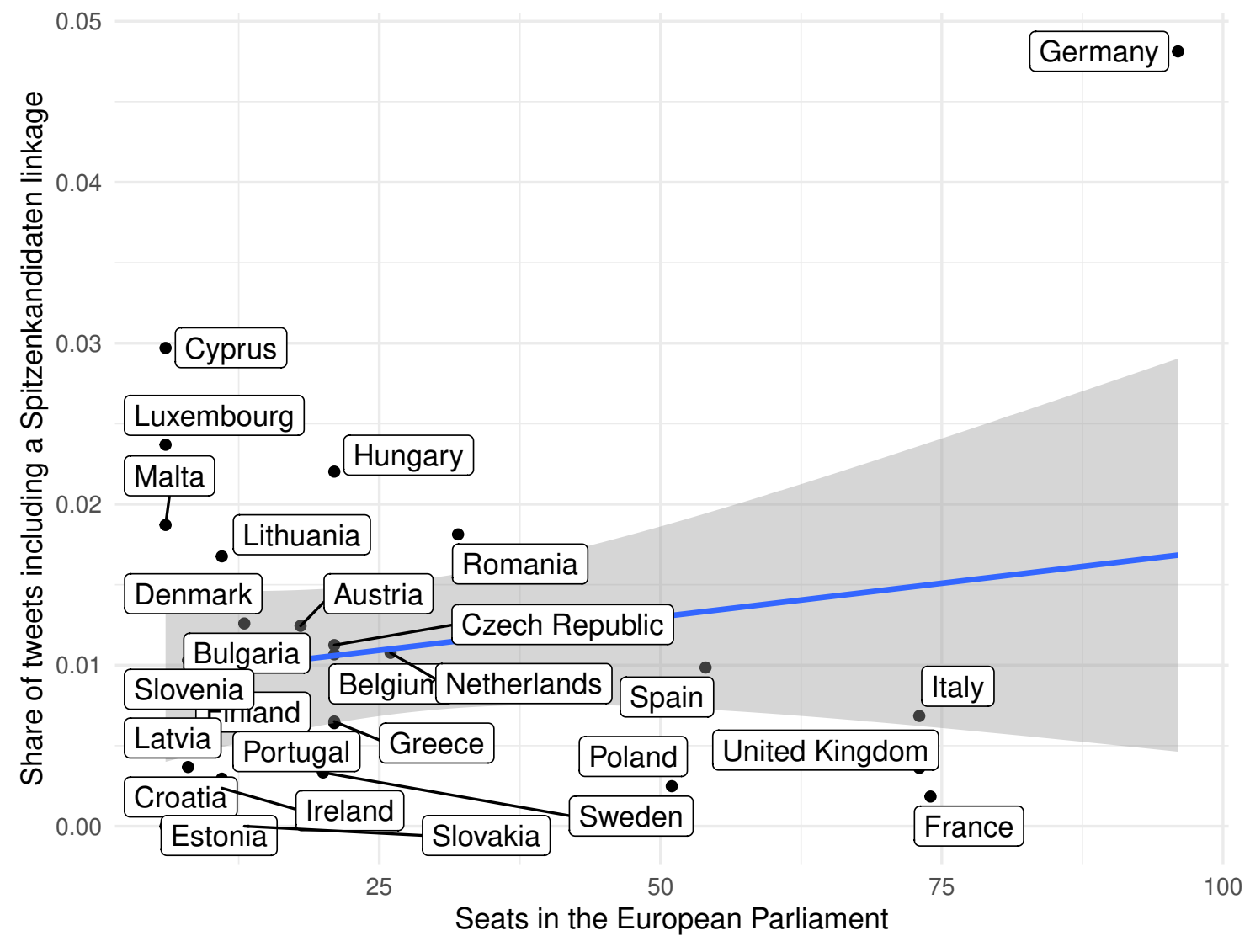

Figure A11: Share of tweets with a Spitzenkandidaten linkage and seats in the European Parliament by country. 


\section{References}

Hutter, Swen, and Hanspeter Kriesi. 2019. "Politicizing Europe in Times of Crisis." Journal of European Public Policy 26 (7): 996-1017.

Kearney, Michael W. 2019. "Rtweet: Collecting and Analyzing Twitter Data." Journal of Open Source Software 4 (42): 1829. https://doi.org/10.21105/joss.01829. 